\title{
Interactions of nanomaterials and biological systems: Implications to personalized nanomedicine
}

\section{Citation}

Zhang, Xue-Qing, Xiaoyang Xu, Nicolas Bertrand, Eric Pridgen, Archana Swami, and Omid C. Farokhzad. 2012. Interactions of Nanomaterials and Biological Systems: Implications to Personalized Nanomedicine. Advanced Drug Delivery Reviews 64 (13) (October): 1363-1384. doi:10.1016/j.addr.2012.08.005.

\section{Published Version}

doi:10.1016/j.addr.2012.08.005

\section{Permanent link}

http://nrs.harvard.edu/urn-3:HUL.InstRepos:29293167

\section{Terms of Use}

This article was downloaded from Harvard University's DASH repository, and is made available under the terms and conditions applicable to Other Posted Material, as set forth at http:// nrs.harvard.edu/urn-3:HUL.InstRepos:dash.current.terms-of-use\#LAA

\section{Share Your Story}

The Harvard community has made this article openly available.

Please share how this access benefits you. Submit a story.

Accessibility 


\title{
Interactions of nanomaterials and biological systems: implications to personalized nanomedicine
}

\author{
Xue-Qing Zhang ${ }^{\dagger, a},{\text { Xiaoyang X } \mathbf{u}^{\dagger, a, b}, \text { Nicolas Bertrand }}^{\mathrm{b}}$, Eric Pridgen ${ }^{\mathrm{b}, \mathrm{c}}$, Archana Swami $^{\mathrm{a}}$, \\ and Omid C. Farokhzad ${ }^{a,{ }^{*}}$ \\ aLaboratory of Nanomedicine and Biomaterials, Department of Anesthesiology, Brigham and \\ Women's Hospital, Harvard Medical School, 75 Francis St., Boston, MA 02115, USA \\ ${ }^{b}$ The David H. Koch Institute for Integrative Cancer Research, Massachusetts Institute of \\ Technology, Cambridge, MA 02139, USA \\ 'Department of Chemical Engineering, Massachusetts Institute of Technology, Cambridge, MA \\ 02139, USA
}

\begin{abstract}
The application of nanotechnology to personalized medicine provides an unprecedented opportunity to improve the treatment of many diseases. Nanomaterials offer several advantages as therapeutic and diagnostic tools due to design flexibility, small sizes, large surface-to-volume ratio, and ease of surface modification with multivalent ligands to increase avidity for target molecules. Nanomaterials can be engineered to interact with specific biological components, allowing them to benefit from the insights provided by personalized medicine techniques. To tailor these interactions, a comprehensive knowledge of how nanomaterials interact with biological systems is critical. Herein, we discuss how the interactions of nanomaterials with biological systems can guide their design for diagnostic, imaging and drug delivery purposes. A general overview of nanomaterials under investigation is provided with an emphasis on systems that have reached clinical trials. Finally, considerations for the development of personalized nanomedicines are summarized such as the potential toxicity, scientific and technical challenges in fabricating them, and regulatory and ethical issues raised by the utilization of nanomaterials.
\end{abstract}

\section{Keywords}

Nanomaterials; nanoparticles; targeted delivery; personalized nanomedicine; nanotechnology; molecular diagnostic; in vivo imaging; protein binding; receptor-mediated endocytosis

\section{Introduction}

The application of nanotechnology to medicine has created an interdisciplinary research field, often referred to as nanomedicine, which has the potential to significantly improve the

\footnotetext{
This review is part of the Advanced Drug Delivery Reviews theme issue on "Personalized Nanomedicine".

(c) 2012 Elsevier B.V. All rights reserved.

"Corresponding author. Tel.: +1 617732 6093; fax: +1 6177302801 ofarokhzad@ @eus.bwh.harvard.edu. Brigham and Women’s Hospital, 75 Francis St., Boston, MA 02115, USA .

${ }^{\dagger}$ Both authors have contributed equally.

Publisher's Disclaimer: This is a PDF file of an unedited manuscript that has been accepted for publication. As a service to our customers we are providing this early version of the manuscript. The manuscript will undergo copyediting, typesetting, and review of the resulting proof before it is published in its final citable form. Please note that during the production process errors may be discovered which could affect the content, and all legal disclaimers that apply to the journal pertain.
} 
way many diseases are treated [1]. Within the nascent but rapidly growing field of nanomedicine, personalized medicine applications are among the most promising and exciting innovations [2]. Personalized medicine consists of a healthcare strategy where specific therapeutics are prescribed to patients on the basis of genetic, phenotypic, and environmental factors that influence the response to therapy [3]. It has long been recognized that individual patients respond differently to the same drug in terms of efficacy and safety due to the complexity and heterogeneity of diseases and patients [4]. For example, some drugs and dosages cause adverse health effects within a particular patient population while a different patient population responds well to the drug treatment with minimal side effects. Similarly, there may be marked variability in efficacy as well. With an increased understanding of genomics and the emergence of novel technologies for the investigation of molecular profiling and genetic mapping of a patient, personalized medicine is poised to begin reaching its full potential.

The application of nanomaterials to medical problems has already demonstrated a clinical impact in terms of delivery strategies for a range of bioactive molecules, including therapeutic agents, nucleic acids and imaging contrast agents [5]. Nanotechnology enables a combinatorial library of nanoparticles to be synthesized with precise control over surface modifications (e.g., targeting moieties, charge modification, stealth), size, shape, and other particle characteristics that can be screened in order to find the best particle properties for patient-specific therapeutics [6]. There are already examples of nanomedicine in the clinic. Doxil®, a PEGylated liposomal doxorubicin formulation, was the first nanosized therapeutic on the market in 1995 and was used as an effective treatment for metastatic breast cancer and recurrent ovarian cancer [7]. Other systems are in various stages of preclinical and clinical advancements. For example, a targeted therapeutic nanoparticle, named BIND-014, that accumulates in tumors while avoiding uptake by the healthy cells have shown promising results in an ongoing clinical trial [6]. Another example is a lipid nanoparticulate delivery system (Oncoprex ${ }^{\circledR}$ ) containing plasmid DNA encoding the TUSC2 tumor suppressor that is being studied in combination with erlotinib, a human epidermal growth factor receptor (EGFR) inhibitor, in lung cancer patients unresponsive to erlotinib or lacking the EGFR mutation [8]. Preclinical studies in animals showed that intravenous TUSC2 nanoparticles work synergistically with erlotinib to overcome drug-induced resistance by simultaneously inactivating the EGFR pathway and by inducing apoptosis in resistant cells. A phase II clinical trial evaluating intravenous TUSC2 nanoparticles in combination with erlotinib will begin in 2012. This will provide two possible therapeutic options depending on the tumor EGFR expression: EGFR inhibitor monotherapy or in combination with the nanoparticles. Progress has also been made in the development of versatile nanocarriers placing emphasis upon patient-specific treatments. For example, Zhang and colleagues recently proposed red blood cell (RBC) membrane-coated nanoparticles to evade the immune system and exhibit longer retention time in the blood [9]. This approach suggests an elegant yet hard to clinically-implement methodology: the patient's RBCs are collected and emptied to leave only the membranes, the latter are then fused with pre-formed polymeric nanoparticles. The resultant RBC-membrane coated nanoparticles are therefore decorated with the patient's own proteins and cell membranes to evade the host's defense mechanisms.

While personalized medicine can guide the design and use of nanocarriers, nanotechnology can also aid in the collection of genomic and molecular data necessary for personalized medicine. Advances in personalized medicine occur through the development of novel nanomaterials as well as technologies for the early detection, imaging, and identification of molecular signatures of diseases. The field of pharmacogenetics and "omics" technologies (e.g., pharmacogenomics, pharmacoproteomics and pharmacometabonomics) have enabled the investigation of an individual patient's genetic and molecular profiles. This information have provided insights into the mechanisms of disease and how to appropriately combine 
therapeutics with specific disease profiles. Nanoscale materials and technologies have the ability to greatly expand the molecular and genetic information gathered from patients. For example, the GeneChip ${ }^{\circledR}$ microarray allows nanoscale patterning of biological molecules on surfaces with exquisite control over their spatial placement to obtain DNA sequencing [1, 10]. With the ability to control molecular deposition now in the nanometer range, a millionfold increase in information density could be packed in "nanoarrays" for the detection of nucleic acids or proteomic profiles [11-13]. Another example is gold nanoparticles modified with biorecognition molecules that are used for high-throughput genomic detection and are currently approved for use by the FDA [14-16].

A research report of commercialization efforts of nanomedicine from the Business Communications Company indicated that the global nanomedicine sales are projected to grow to over $\$ 100$ billion by 2014 [17]. There are increasingly growing partnerships between biopharmaceutical companies and nanomedicine startups pursuing nanomedicine $R \& D$ projects due to the enormous potential applications of nanotechnology to healthcare. One of the predominant focuses is drug delivery applications. The other nanomedicine products include in vivo imaging agents, in vitro diagnostics, biomaterials, and active implants [18]. As our fundamental understanding of diseases increases, implementations of nanotechnology will offer an expanding toolbox to improve point-of-care diagnostics, enable integration of diagnostics with therapeutics, and treat patients with a more personal approach.

While nanomedicine starts to show much promise to the field of personalized medicine, further research is required to expand its impact. In particular, a fundamental understanding of the interactions between nanomaterial surfaces and complex proteins in biological fluids needs to be achieved. This would influence both in vivo delivery of therapeutics and ex vivo diagnostics. Likewise, interactions between nanomaterials and cells, through non-specific contacts or ligand-receptor interactions, as well as the intracellular mechanisms responsible for trafficking of a nanomaterial in the cell, must be more thoroughly characterized. There is a complex relationship between a nanomaterial's physicochemical properties (e.g., size, charge, surface properties), and its interaction within a biological system. Small changes in size, charge, surface functionalization and chemical composition can lead to radically different interactions with living systems [19]. These interactions then determine the biocompatibility, stability, biological performance and side effects of the nanomaterial. In this regard, understanding the nano-bio interactions and the relationships between the nanomaterial properties/structure and activity will provide a conceptual basis for the rational design and safe use of personalized nanomedicines.

In the first section of this review, we will address different areas in which better comprehension is required and propose examples showing how nanomaterials interact with their environment in complex and subtle manners. Each subject will be discussed from the perspective of its implications for personalized medicine. The second section will highlight some examples that demonstrate current trends and novel concepts in the field of nanomedicine and its impact on personalized medicine. These include nano-sized platforms for the targeted delivery of therapeutics, contrast agents for diagnostic imaging, and theranostic nanoparticles. The use of nanoparticles for the discovery of biomarkers and molecular diagnostic will also be evaluated. Finally, the third section will present the scientific and technical challenges associated with developing personalized nanomedicines, various safety, political and ethical issues raised in the field, as well as the obstacles and limitations associated with personalized nanomedicine. 


\section{Interactions of nanomaterials in biological systems}

As the role of nanomaterials in biology and medicine continues to grow, the number of situations in which they will be in contact with biological systems will indisputably increase. In this domain where the complexities of nanotechnology and human physiology combine, fundamental understanding is essential before one can think about intricate applications. In the following section, three different aspects of the interactions between nanomaterials and proteins will be presented. Their relevance to personalized medicine will be highlighted in the last section.

\subsection{Protein-binding}

When nanoparticles are utilized for treatment, imaging a tumor, or aiding to establish a diagnosis upon systemic administration, the first tissue they encounter is the blood and all the proteins it contains within. Similarly, when diagnostic nanomaterials are used in vitro or ex vivo to analyze samples of biological fluids, they will come in contact with complex proteins mixtures. The adsorption of proteins on a substrate is a much more complex phenomenon when the surface possesses nanoscale dimensions as compared to that of larger proportions [20]. The relative surface area of nanomaterials is very large and their features are on the same order as proteins (1 to $20 \mathrm{~nm}$ ) [21]. The interactions between proteins and materials of the nano- and meso- or macroscales are therefore both quantitatively and qualitatively different.

Upon contact with biological fluids (e.g., blood, interstitial fluid or mucosal secretions), nanoparticles are coated with proteins that may change their surface charge and properties. This biological coating can subsequently lead to the loss of performance due to an increase in hydrodynamic size or aggregation. The protein that binds most strongly to polymeric nanoparticles, liposomes, iron oxide nanoparticles and carbon nanotubes are albumin, immunoglobulins, fibrinogen, apolipoproteins and proteins from the complement cascade [20].

2.1.1 Decreasing the nonspecific protein interaction-When nanoparticles are administered systemically, the proteins that adhere to their surface will greatly affect their circulation and biodistribution [22, 23]. Complement and immunoglobulin binding promotes particle opsonization, leading to recognition by the mononuclear phagocyte system (MPS) and rapid clearance from the bloodstream [22]. MPS capture is dictated by macrophage phagocytosis (mostly in the sinusoids of the liver) and splenic filtration [23, 24]. Aggregation of nanoparticles in the blood can also lead to retention and embolism in the lung capillaries [25].

Short circulation half-life, low efficacy, and toxicity caused by accumulation of foreign materials in the liver and spleen are the primary limitation for the systemic administration of nanoparticles. These issues have led to the development of strategies aimed at increasing blood residence time. Among these, the use of poly(ethylene glycol) (PEG) for surface functionalization has been shown to dramatically reduce protein absorption, particularly apolipoprotein $\mathrm{J}$ and complement protein $\mathrm{C} 3$, through hydrophilicity and steric repulsion effects, therefore extending residence time in blood [26-28]. This has allowed the "stealth" nanoparticle carriers to be present in the bloodstream long enough to reach or recognize their therapeutic site of action [29].

Examples of "stealth" nanocarriers include PEGylated liposomal doxorubicin (Doxilß) and the PLA-PEG micelle form of paclitaxel (Genexol-PM®, marketed in Korea in 2007). Encapsulating doxorubicin within PEGylated nanoparticles allows for extended circulation half-life in blood and higher tumor concentration of doxorubicin. The homing to the disease 
site is driven only by the particles' nano-dimensions and PEGylated surface through the enhanced permeability and retention (EPR) effect [30], which results from enhanced vascular permeability and the absence of a functioning lymphatic system, and is not related to any specific recognition of the target.

In addition to causing quick clearance, nonspecific interactions of nanomaterials with proteins from complex biological samples (e.g., human blood serum, plasma and tissue extracts) hamper the full exploitation of ex vivo nano-based diagnostics and arrays [31]. Novel diagnostic nanomaterials are emerging for the detection and quantification of less abundant biomarkers in biological samples and are envisioned to provide ground-breaking tools for personalized nanomedicine [32]. These nanoparticles and nanostructures possess many unique and advantageous physical properties when applied as ultra-sensitive signal transducers and protein biosensors in the fields of molecular diagnostics and proteomics. Their nanoscale dimensions also result in increases in information quality, quantity and density. Major examples include nanocantilevers, nanowires, nanotube arrays and oligonucleotide-modified gold nanoparticle-based bio-barcode assays that enable multibiomarker detection [1]. However, the development of these approaches with high sensitivity and selectivity faces several bottlenecks including deconvolution of noise from the signal, especially in regard to biofouling. For the analysis of proteomic signatures, a major challenge will be the identification of signatures from low-concentration molecular species, in the presence of extremely high concentrations of non-specific serum proteins.

Nonspecific binding remains a major concern which may lead to false positive signals and low signal-to-noise ratios for a given assay. For various applications such as affinity biosensors or nanoarrays, it is critical to block possible sites for nonspecific binding and/or treat nanomaterials with surface coatings that combine an ultralow fouling background with abundant biorecognition elements. To solve this problem, nonfouling coating materials such as zwitterionic polymers, PEG and its derivates have been developed to prevent nonspecific protein adsorption when exposed to complex media $[33,34]$. For example, combined with a surface plasma resonance (SPR) sensor, the protein arrays created using zwitterionic poly(carboxybetaine acrylamide) are able to detect specific cancer biomarkers and monitor the kinetics of antigen-antibody interactions from 100\% human blood plasma with high specificity and sensitivity [33]. The background noise was very low due to significantly minimized total nonspecific protein adsorption on the functionalized zwitterionic surface.

2.1.2. Limiting the immunogenicity-Decreasing the immunogenicity of a nanomaterial is also of critical importance since therapeutic nanoconstructs have dimensions very similar to those of pathogens for which recognition signals were positively selected for evolution [35]. The understanding of the immune reactions to therapeutic and diagnostic nanomaterials is still poorly characterized and additional knowledge is required to ensure which characteristics warrant repeated systemic administration without adverse reactions.

For example, in preclinical studies, the phenomenon aptly named accelerated blood clearance $(\mathrm{ABC})$ has been observed in animal models for various types of nanoconstructs [36-38]. In this effect, an initial sensitization of the animals to the nanomaterial triggers a transient immune response and induction of Immunoglobulin M (IgM) antibody which prompts rapid clearance of the subsequently administered doses by increased capture in the liver and the spleen [12-14]. The factors that impact the appearance of this phenomenon are multifaceted and include the nature of the payload of the nanomaterial [39, 40], the dose administered [39-41], and other physicochemical characteristics of each nanoconstruct [41, 42]. The encapsulation of cytotoxic compounds seems to highly diminish the $\mathrm{ABC}$ effect, possibly through a deleterious effect on the B cells responsible for the secretion of IgM [39, 40]. In the current context where all nanomedicines on the market contain anticancer drugs, the manifestations of $\mathrm{ABC}$ have had limited significance. However, the future development 
of nanomedicines for all types of diseases and encapsulating a variety of drugs will certainly have to address that problem before nanomaterials can be repeatedly and consistently administered.

Understanding nanomaterial-protein interactions is also important for the development of safer and better tolerated nanomedicine. PEGylated liposomes are known to exhibit prolonged circulation time in blood and have had success in translation to the clinic. However, infusion of therapeutic liposomal drugs such as Doxil@ as well as other amphiphilic lipids which have reached the bedside (e.g., Cremophor EL®) could lead to a hypersensitivity syndrome called complement activation-related pseudoallergy (CARPA). The CARPA syndrome differs from anaphylaxis since it does not involve IgE but arises as a consequence of activation of the complement (C) system. Also, CARPA improves upon subsequent exposure and can be mitigated in patients by reducing the infusion rate as opposed to anaphylaxis where re-exposition usually triggers a more serious reaction [43].

Moghimi et al. have demonstrated that liposomes prepared using anionic phospholipid-PEG conjugates caused CARPA, partly because the highly cationic region of the globular C1q protein binds with the anionic charge localized on the phosphate oxygen of the lipid-PEG conjugate through electrostatic interaction. This induces activation of the complement cascade, opsonization of the nanoparticle surface and anaphylatoxin production (reflected in significant rises in SC5b-9, C4d, C3a and C5a levels in human sera) [44]. CARPA is mostly mild and transient, but in some patients, it can be severe or even lethal. In addition, a main manifestation of complement activation is cardiopulmonary distress; therefore, CARPA may be a safety issue primarily in cardiac patients.

Several methods have been explored to circumvent the problem. A previous study revealed that removal of the negative charge by methylation of the phosphate oxygen of lipid-PEG conjugates totally prevented complement activation. Others have recently synthesized a range of neutral lipopolymers and variations thereof for liposome engineering [45]. Remarkably, preliminary investigations have demonstrated that such lipopolymerincorporated liposomes are poor activators of the human and porcine complement system when compared to vehicles bearing anionic lipid-PEG conjugates [46]. The nanoformulations prepared with neutral lipopolymers may hold great potential to treat patients with severe CARPA response or cardiac disease. More studies have been conducted to test the CARPA concept and the immunological interactions of liposomal and amphiphilic polymeric nanoparticles [47, 48]. In addition to the CARPA reactions observed in the clinics, complement activation also leads to opsonisation of the nanomaterials and enhances their clearance by the MPS. Therefore, any measure to prevent its activation could translate into increased circulation times and efficiency. Figure 1 demonstrates the different pathways that trigger the complement system and how physicochemical properties of nanomaterials can switch the activation process from one pathway to another [49-55].

2.1.3. Exploiting the beneficial aspects of protein-binding-The nanomaterialprotein interactions should not only be viewed as being disadvantageous, as some preferential interactions can be used to guide the distribution of nanoparticles to specific tissues. For example, decoration of nanomaterial with specific proteins prior to injection has been exploited for particular targeting purposes [56-58].

More recently, a possibly higher response rate in a subset of patients observed during the first clinical studies on albumin-coated paclitaxel (nab-PTX, Abraxane $\left.{ }^{\circledR}\right)$ sparked a flash of enthusiasm in the drug delivery community. In this study, it was found that different response rates between individual patients receiving $n a b$-PTX could be explained by degrees of expression in the extratumoral protein SPARC (secreted protein acidic and rich in 
cysteine) [59]. SPARC is a secreted matricellular glycoprotein with high binding affinity to albumin which functions to regulate cell-matrix interactions [60]. Its overexpression is associated with increased tumor invasion and metastasis, leading to poor prognosis in multiple tumor types including breast, prostate, and head and neck cancers [61]. In this context, the prospect that SPARC-positive patients would respond better to nab-PTX was particularly appealing.

Desai et al. tested this hypothesis by correlating the clinical response and SPARC tumor expression in a retrospective analysis of 60 patients receiving nab-PTX as monotherapy against head and neck cancer [59]. It was found that response to nab-PTX was higher for SPARC-positive patients (83\%) than SPARC-negative patients (25\%). As shown in Figure 2 , a possible explanation for the positive correlations between SPARC expression and the drug is that the interactions of albumin and SPARC in the tumor interstitium could facilitate the accumulation of $n a b$-PTX in the tumor. Furthermore, the albumin-drug interactions were thought to facilitate the transport of paclitaxel molecules across endothelial barriers via gp60 receptor and caveolin-1 mediated transcytosis [59].

As further supporting evidence, a study in animals with multiple tumor xenografts also showed correlations between the relative efficacy of nab-PTX and SPARC expression. In this study, the albumin-containing formulation was compared to polysorbate-based docetaxel. In comparison with control groups, the effect of nab-PTX in HER2-positive breast tumors with increasing SPARC expression seemed superior to that witnessed in MDA-MB-231/HER2-positive tumors with low SPARC expression [62]. It should be noted, however, that differences between the pharmacological agents used (paclitaxel vs. docetaxel) and the large discrepancies between the doses of drug administered in the different groups strongly limit the conclusions that can be drawn from this study.

To complicate matters, a recent study yielded confounding evidence about the implication of SPARC on the efficacy of nab-PTX. In animals bearing patient-derived non-small cell lung cancer (NSCLC) tumor xenografts, the response to nab-PTX could not be correlated to SPARC expression. In this study, the improved antitumor effect of the albumin-based formulation over solvent-solubilized PTX could also be observed in some SPARC-negative tumors and the induction of SPARC expression in low-responsive tumors could not enhance activity [63]. This implies the possibility of other mechanisms being implicated to explain the response to nab-PTX. In this study, the compared doses of drugs $(30 \mathrm{mg} / \mathrm{kg} / \mathrm{day}$ of $n a b$ PTX vs. $13.4 \mathrm{mg} / \mathrm{kg} / \mathrm{day}$ of solvent-formulated PTX) were reputedly equitoxic. However, these doses were ascertained based on the tolerability of the compound in mice [64]. Hence, it still remains difficult to address if the benefits of nab-PTX over solvent-formulated PTX are uniquely owed to improved tolerability or to real targeting manifestations.

In conclusion, more efforts are needed before we can ascertain the role of SPARC expression as a biomarker for personalized anticancer therapies using albumin-based formulations. For one, there is a current lack of understanding of the stability of the 130-nm albumin-encapsulated PTX nanoparticles once it is introduced in the blood. Some reports mention that, upon dilution, the nanoparticles dissolve into individual albumin-PTX complexes [65], but the nature of these interactions between the drug and proteins remain unclear. Finally, larger prospective clinical validations in multiple tumor types are required to investigate the correlations between SPARC expression and response to treatment. As of now, the only published clinical justification that establishes association between nab-PTX and SPARC expression is a retrospective analysis of a 60-patient clinical phase II study [59].

2.1.4. The impact of nanomaterial-protein interactions on personalized nanomedicine-From the preceding examples, it is clear that further understanding of the 
interactions between proteins and nanomaterials are required to further establish their potential for personalized medicine. The role of blood proteins on the clearance and immunological mechanisms must be better defined in order to more effectively implement nanoconstructs for therapeutic purposes. Patients display inter-individual variability in the circulating levels of various proteins (e.g., lipoproteins, immunoglobulins, cytokines). These differences can explain the variations in each patient's response to therapeutics or their higher susceptibility to side effects (i.e., CARPA is observed only in a "reacting" subset of patient population) [43]. Similarly, the homeostasis of blood component can also be intensely affected by health conditions or diseases [66]. For example, physiological stress can trigger overexpression of acute-phase proteins and some of these proteins (e.g., Creactive protein) can enhance complement activation and macrophage uptake when fixed on the surface of pathogens and senescent cells $[67,68]$. The impact of such conditions on the fate of therapeutic nanomaterial must be ascertained before nanomedicine can be used efficiently in a variety of diseases.

In addition, nanomaterial-protein interactions must also be further understood to optimally exploit their beneficial effects on the activity or distribution of nanoconstructs. The example of SPARC is particularly relevant because if the protein is confirmed as a predictive biomarker of response to treatment, the albumin-based formulation would become the first nanomedicine approved for individualized therapy. However, extensive additional preclinical and clinical evidence is required before patients screened based on SPARC expression can receive personalized treatments.

\subsection{Ligand-mediated interactions}

Nanomaterials can be designed to specifically recognize a target with a surface ligand. These interactions can be utilized to preferentially concentrate a therapeutic nanoconstruct at a diseased tissue in vivo [69] or to bind and detect a biomarker for ex vivo diagnostic purposes [1]. The dimensions of the nanomaterials and the opportunity for polyvalent decoration of their surface with ligands contribute to their potential as effective homing and recognition devices. Throughout evolution, pathogens have exploited the multivalent patterning of a ligand on their surface to considerably enhance their affinity and tropism for their target $[35,70]$. Likewise, on artificial constructs, a simple increase in the stoichiometry of a ligand can sometimes drastically enhance the ability to bind a substrate [71].

The decoration of a nanoparticle's surface with a ligand can also trigger receptor-mediated endocytosis by cells expressing the right target on their membrane, a process that has considerable implications for targeted delivery [72]. Ligand-mediated interactions provide many opportunities for personalized medicine including differential spatial localization, intentional homing of nanoparticles to active diseased sites, and elimination of off-target adverse effects. Figure 3A and B illustrate the active binding of nanoparticles to cell surfaces for vascular targeting and tumor cell targeting. Ligand-functionalized nano-based therapeutic systems or imaging contrast agents therefore represent unrivaled platforms to improve the specificity and sensitivity of treatment and diagnostic tools.

The ligands used to decorate nanoparticles can include antibodies, engineered antibody fragments, proteins, peptides, small molecules, and aptamers [73]. For both applications, two types of targets exist: targets that are ubiquitously-expressed in all tissues and targets that are specific to diseased cells. Herein several examples of ligand-receptor interactions exploiting both categories will be presented, and special attention will be given to a few nanoplatforms that are targeted through ligand-receptor interactions and have made their way successfully to clinical trials [74]. 
2.2.1 Ubiquitous targets-The active targeting of drug delivery systems with transferrin (Tf), a 80-kDa blood-circulating glycoprotein, is a concept which dates back to the late-1980s [75]. Several characteristics make the targeting of transferrin receptors (TfR) attractive and an abundance of systems exploiting this internalization pathway have been designed. First, although the TfR is expressed in all types of tissue to satisfy the ferric (II) iron requirements of dividing cells, the hyper-proliferation of cancer cells makes it an attractive overexpressed target in tumors [76]. Secondly, the endocytosed TfR is very rapidly recycled to the cell surface after internalization $[77,78]$ which makes it an appealing, almost non-saturable, entryway into the cells. Thirdly, the TfR is believed to facilitate the transport of macromolecules and nanoconstructs across the blood-brain barrier [77], representing a rare opportunity to enable penetration to the central nervous system. For all these reasons, the targeting of therapeutic nanomaterials through $\mathrm{Tf}$ has been widely studied.

Recently, Davis et al. reported the first human trial of targeted siRNA delivery using polymeric nanoparticles containing Tf-modified cyclodextrin (CALAA-01) [79, 80]. In this study, human Tf was used as a targeting ligand for binding to TfR, which is typically upregulated on cancer cells and trigger cellular uptake via clathrin-coated pits. These targeted nanoparticles were administered intravenously to patients with melanoma where they circulated and localized in tumors (Figure 4). The Tf on the nanoparticle surface was able to bind to overexpressed TfR on cancer cells, and the nanoparticles were internalized via receptor-mediated endocytosis (Figure 4d). Tumor biopsies from melanoma patients obtained after treatment showed the presence of intracellularly localized nanoparticles in amounts that correlated with dose levels of the nanoparticles administered. Furthermore, a reduction was found in both the specific messenger RNA and the protein levels when compared to tissue obtained before dosing of the targeted nanoconstructs.

The receptor tyrosine kinase EGFR is another potent and well-studied target for anticancer drug delivery systems which is constitutively expressed on the surface of cells throughout the body. In response to the binding of its ligands (i.e., various growth factors), EGFR is significantly involved in cell signaling pathways associated with growth, differentiation and proliferation. EGFR exists on the cell surface and is overexpressed in multi-drug resistant (MDR) cancer cells [81, 82]. Milane et al. utilized this overexpression through the development of EGFR-targeted polymeric nanocarriers for the treatment of MDR cancer using paclitaxel (a common chemotherapeutic agent) and lonidamine (an experimental drug; mitochondrial hexokinase 2 inhibitor) [82]. The safety and efficacy of nanoparticle treatment were tested in a mouse orthotopic model of MDR human breast cancer. It was observed that this nanocarrier system demonstrated superior efficacy and safety relative to free drug combinations (paclitaxel/lonidamine solution) and single agent treatments in nanoparticle and solution forms. The targeted nanoparticles loaded with a combination of paclitaxel and lonidamine were the only treatment group that achieved sustained decrease in tumor volume. In addition, treatment with the EGFR-targeted lonidamine/paclitaxel nanoparticles decreased tumor density and altered the MDR phenotype of the tumor xenografts, decreasing the MDR character of the xenografts as evidenced by a drop in the expression of P-glycoprotein (Pgp) and EGFR. In another study, a versatile nanodiamond (ND) construct that incorporates anti-EGFR monoclonal antibodies (mAb), a fluorescent imaging agent and paclitaxel has been developed for multimodal imaging and the treatment of triple-negative subtype of breast cancer (TNBC) [83]. EGFR is expressed at high levels in at least $20 \%$ of breast cancers overall, but in 60-70\% of patients with TNBC [84], which makes EGFR a potential treatment target. The enhanced cellular internalization of antiEGFR mAb conjugated ND was only observed in the EGFR-overexpressing MDA-MB-231 cells but not in the basal EGFR expressing MCF7 cells. The data suggested that targeting through the mAb moiety increased specificity and internalization within EGFR- 
overexpressing breast cancer cells, which subsequently enhanced therapeutic activity of targeted conjugates. To monitor receptor-mediated endocytosis, Lidke et al. used quantum dots (QDs) conjugated to epidermal growth factor (EGF) to study erbB/HER receptormediated cellular response to EGF in living human epidermoid carcinoma A431 cells, assigning the mechanism of EGF-induced signaling to heterodimerization of erbB1 and erbB2 monomers and uncovering retrograde transport of endocytosed QD probes [85].

Finally, other examples of ubiquitously-occurring receptors being exploited for active targeting of ligand-functionalized therapeutics exist. For instance, various macromolecular drug conjugates and nanoparticulate systems were studied to take advantage of the overexpression of the folate receptor in tumor cells for the purpose of enhanced delivery as well as diagnosing and imaging malignant masses with improved specificity and sensitivity $[86,87]$. Similarly, the retinol-binding protein, which is constitutively expressed in the brain, the spleen, the eyes, the genital organs and in lower quantities in the heart and lungs, was recently exploited to target stellate cells in the liver to alleviate cirrhotic fibrosis [88, 89]. In this approach, the favored non-specific distribution of the liposomes in the liver might contribute to enhancing the interactions between the nanomaterials and their target on the surface of the cells.

2.2.2 Cell-specific targets-Targeting to molecules that are differentially expressed at high levels by certain tissues offers a way to enhance accumulation at specific sites in the body. The exploitation of targets which are distinctively expressed in certain organs offers the possibility to further enhance the specificity of a treatment. The use of prostate-specific membrane antigen (PSMA) is a good example of a tissue-specific receptor that has been efficiently used to target anticancer drug-loaded nanoparticles. The first generation of prostate-specific nanoparticles incorporated PSMA-binding aptamers on their surface to promote internalization by cancer cells. In a mouse xenograft model, one single intratumoral injection of aptamer-functionalized nanoparticles loaded with docetaxel was able to show a considerably higher proportion of complete tumor regression and significantly prolonged survival rates [90]. Similar aptamer-decorated particles were also shown to be able to incorporate prodrugs of a hydrophilic platinum compound [91]. In order to translate these findings to the clinic, a formulation using a low molecular weight ligand with high affinity for PSMA was developed. These formulations using urea-based ligands provided the advantages of being easier to scale-up, while simultaneously not presenting the potential immunological problems associated with the presence of nucleic acids on the surface of the nanomaterial. A docetaxel-containing formulation functionalized with the PSMA-specific ligand, BIND-014, is currently in phase I clinical trials. Preliminary data showed stable disease in patients at doses below the commonly used regimen for the commerciallyavailable, solvent-based docetaxel formulation [6].

Other specific targets have been investigated to optimize the interactions of therapeutic and diagnostic nanomaterials with diseased cells. For example, anti-CD33 monoclonal antibody has been successfully exploited to target leukemic cells since CD33 is a surface antigen expressed on over $80 \%$ of leukemia blast cells from acute myeloid leukemia (AML)suffering patients but not on healthy cells [92]. Gemtuzumab, a monoclonal antibody to CD33 linked to a cytotoxic drug, was approved by the FDA in 2000 for use in patients over the age of 60 with relapsed AML. Upon the conjugation of anti-CD33 monoclonal antibody, the modified polymer/liposome hybrid nanovectors demonstrated enhanced internalization by $\mathrm{CD} 33+$ leukemic cell lines while limited interaction was found for nanovectors decorated with an isotype-matched control antibody [93]. In addition, the drug-loaded anti-CD33 nanoformulation exhibited the highest cytotoxicity against CD33+ leukemic cells, suggesting a promising targeted nanotherapeutics for the treatment of AML. The cancer cellspecific anti-nucleosome monoclonal antibody $2 \mathrm{C} 5(\mathrm{mAb} 2 \mathrm{C} 5)$, which recognizes the 
surface of various tumor cells (but not normal cells) via tumor cell surface-bound nucleosomes, was also attached to polymeric micelles, making the resulting micelles capable of specifically targeting a broad range of tumors [94]. Intravenous administration of tumorspecific 2C5 micelles loaded with paclitaxel into experimental mice bearing Lewis lung carcinoma resulted in an increased accumulation of paclitaxel in the tumor compared with free drug or paclitaxel in nontargeted micelles and in enhanced tumor growth inhibition.

The increasing availability of monoclonal antibodies for targeted therapy at large has fostered the interest of antibody-functionalized targeted nanomaterial for many years [95-98]. However, the presence of these large biological macromolecules ( $\mathrm{Ab}$ or $\mathrm{Ab}$ fragments) can seriously compromise their circulation times in the bloodstream, and their ability to traffic to their intended destination in vivo [99]. Therefore, large efforts have been put in the development of less immunogenic targeting moieties (e.g., peptides, small molecules) $[100,101]$ which might possibly have brighter futures for in vivo applications.

2.2.3 Ligand-mediated in vitro diagnosis-In comparison, the immunologic properties of antibodies are much less of a hindrance for ex vivo diagnostic applications, and the field has benefited greatly from the specific-binding properties of these molecules to recognize and detect biomarkers of interest [1]. Several nanomaterials can be modified with different combinations of specific markers to rapidly screen molecular profiling of small populations of cancer cells at good signal-to-noise levels [102], which is of clinical importance for early cancer detection. An example of such technique named "bioorthogonal nanoparticle detection" (BOND) was developed by Weissleder and colleagues [102]. In this work, live cells were labeled with trans-cyclooctene-modified antibodies (anti-HER-2, EpCAM and EGFR, respectively) followed by coupling with tetrazine-modified fluorescentlabeled iron oxide nanoparticles (Figure 5A and B). The transverse relaxation rate $\left(\mathrm{R}_{2}\right)$ was measured for $\sim 1000$ cells, a sample size in line with clinical specimens, using a miniaturized diagnostic magnetic resonance detector. As shown in Figure 5C, markers signals were nearly at normal levels for benign fibroblasts and leukocytes (except for CD45, naturally expressed in the latter) while tumor cells showed considerable heterogeneity in the expression of the different markers. The nuclear magnetic resonance (NMR) signals correlated well with the actual expression levels that were independently determined by flow cytometry using a larger sample size (Figure 5C). This BOND platform demonstrated its application in clinically-oriented molecular profiling by utilizing the polyvalent interactions between engineered nanomaterials and their targets of interest on cell surfaces.

Similarly, small molecules can also be utilized for specific recognition. For example, the self-assembly properties of mannose-functionalized nanoobjects upon interactions with the lectin-coated $E$. Coli bacterial wall was utilized to detect the presence of the pathogen at different concentrations [103]. In this work, the material becomes highly fluorescent by spatially-rearranging itself in a polymeric fiber structure upon interaction with bacteria. Similarly, in a two-step approach, Weissleder et al. decorated the surface of gram-positive bacteria by targeting the surface D-Ala-D-Ala functional groups on the pathogen with vancomycin-trans-cyclooctene conjugates [104]. The presence of these conjugates is subsequently detected using tetrazine-functionalized magnetofluorescent nanoparticles which can attach covalently in situ with the cyclooctene moieties [102, 104].

2.2.4 Selection of ligands-Depending on the intended application, the ligands chosen in the nanomaterial design will highly influence the efficacy of the system. For ex vivo diagnosis, the nanoparticles are expected to immobilize on the cell surface via ligandreceptor interactions as a diagnostic tag. The high affinity and specificity of the ligands are of paramount importance for the reduction of false negatives and positives, respectively. In contrast, nanoparticles that serve as delivery vehicles for drugs will have other 
considerations. For example, considering that intracellular delivery of drug-loaded nanoparticles could provide enhanced therapeutic effects, selection techniques have been developed to distinguish internalizing ligands from non-internalizing ligands [105, 106]. Hild et al. elegantly showed that QDs modified with agonists binding to G protein-coupled receptors could be internalized whereas the same nanoparticles modified with antagonists could not [107]. The functionalization of the nanomaterial with the appropriate ligand dictates the fate of the nanoparticle, allowing for either simple flagging of the cell surface or further uptake to deliver a payload using the same target. Recently, Xiao et al. designed a cell-uptake selection strategy to isolate a group of cancer-cell specific internalizing RNA aptamers (Figure 6A) [108]. In this strategy, selection was carried out against prostate cancer cells using counter selection with non-prostate and normal prostate cells to remove non-specific strands. The internalizing ligands were preferentially collected by deleting noninternalizing, membrane-bound aptamers. The cell uptake properties of nanoparticles functionalized with the identified aptamers were confirmed to be highly specific and efficient (Figure 6B).

Further efforts are now underway to identify ligands with the appropriate affinity and to apply these binding ligands to specifically engineer nanomaterials for diagnosis and targeted therapy [109]. One might note, however, that for a specific ligand, the internalizing properties of the nanomaterial can also depend on multiple physicochemical properties, like size [110] and surface density [111]. The biological processes emerging from successful internalization of the nanomaterials by the cells will be discussed in Section 2.3.

2.2.5 Considerations for personalized medicine-In the near future, the availability of ligand-functionalized therapeutic nanomaterial will have a clear impact on the individualized treatment of diseases. In this context, the detection and monitoring of the target expression before initiating therapy and during the whole treatment will clearly be of utmost importance. Similarly, multivalent nanoparticles are complex objects in which behavior depends on a variety of physicochemical properties [6,112]. Presently, efforts should be made to better understand how ligand-functionalized nanomaterials interact with their targets. In parallel, a better comprehension of the correlations between target expression patterns and cancer prognosis is also required. When both of these aspects are addressed, the therapeutic targets to select for the rational design of nanomedicine will become clearer.

\subsection{Interactions during intracellular processing}

Once endocytosed, nanomaterials are internalized and remain entrapped in transport vesicles which traffic along the endolysosomal scaffold, thereby exerting key effects on subcellular organelles. Intracellular trafficking and the fate of nanomaterials are linked to their physicochemical properties and endocytic pathways [113-116]. For example, nanoparticles taken up by clathrin-dependent receptor-mediated endocytosis (RME) are typically destined for lysosomal degradation; whereas, clathrin-independent RME internalization leads to endosomal accumulation and sorting to a nondegradative path [116]. While some drug delivery systems aim to avoid lysosomal degradation [117], recent studies have utilized directed delivery to this environment for the enzymatic release of therapeutics $[116,118]$. Understanding the key intracellular interactions of nanoparticles has allowed researchers to engineer nanoparticles for highly specialized delivery. Appropriate design and engineering of nanocarriers could therefore allow for controlled intracellular delivery of therapeutics to individual intracellular compartments, which provides benefits to therapies associated with these unique organelles, including cancer therapy, gene therapy, and lysosomal storage disease (LSD) treatments. Furthermore, by offering an alternative to passive diffusion as an entryway into the cells, the design of nanomaterials that can be internalized by receptor- 
mediated endocytosis and thus release their active drugs inside subcellular organelles might provide a useful means to circumvent efflux pump-mediated drug resistance [119]. Here we briefly discuss several examples where the physiological endosomal and lysosomal environment can be exploited to develop responsive drug delivery systems.

2.3.1 Intracellular drug release-Polymer-drug conjugates were among the earliest formulations designed to preferentially release their payload inside the cell. Poly[N-(2hydroxypropyl)methacrylamide] (HPMA) was the first synthetic polymer-drug conjugate to enter clinical trials in 1994. Others, like degradable polyglutamate (PGA), have also been widely clinically investigated as anticancer nanomedicines [118]. These nanosized drug delivery systems are based on the covalent conjugation of chemotherapeutics to hydrophilic polymers, which markedly improves solubility as well as alters drug biodistribution and pharmacokinetics. Conjugates have longer half-life (typically $>1 \mathrm{~h}$ ) than free drug $(<5 \mathrm{~min})$ when circulating in the blood, leading to significantly increased drug concentrations in tumors [120-122]. Since most drugs need to be released from the macromolecule to exert their pharmacological effect, the nature of the linker between the drug and the polymer is therefore of crucial importance (Figure 7). Although the chemical reacting groups on both the macromolecule and the drug dictate the character of the linker available, various classes of bonds with passive or physiologically-triggered cleavage have been studied [123]. Clinical experience has shown that rapid degradation of ester bonds in the bloodstream could lead to suboptimal distribution of the drug in the tumor [124-127]. Therefore, if the drug exerts its effects through an intracellular pharmacological receptor, it can be beneficial to design the conjugate with a lysosomally-degradable peptidyl linker (e.g., Gly-Phe-LeuGly). This type of linker is stable in the bloodstream but can be cleaved by the lysosomal protease cathepsin B once internalized over 24-48 h [114, 118, 128]. Lysosomes and lysosomal hydrolase malfunctions have been associated with several aspects of malignant transformation, including the loss of cell growth control, altered regulation of cell death, and acquisition of chemo-resistance and of metastatic potential [129]. Lysosomal proteasemediated drug release is thus a key conceptual design principle for the chemotherapy of cancer with nanomedicine [118]. An exciting clinical program is assessing a PGA-paclitaxel conjugate (CT-2103; Opaxio) using the Gly-Phe-Leu-Gly linker [120, 130]. In this system, paclitaxel is released to a small extent by slow hydrolytic release, but is released mainly through lysosomal cathepsin B degradation of the polymer backbone [131]. Experiments in cathepsin-B-homozygous knockout mice confirmed the importance of enzyme degradation and intracellular delivery. Clinical studies showed that a significant number of patients responded to stable disease profiles, particularly in patients with mesothelioma, renal cell carcinoma, NSCLC and in paclitaxel-resistant ovarian cancer [120]. In a recent randomized phase III clinical trial, PGA-paclitaxel demonstrated reduced severe side effects and superior therapeutic profiles compared with gemcitabine or vinorelbine as a first-line treatment for poor performance status NSCLC patients [132, 133]. Additionally, in comparison with men this trial showed increased survival in women treated with PGA-paclitaxel, specially marked in pre-menopausal women [134]. It should also be noted that activity might correlate with estrogen levels which increase expression of cathepsin B [135]. If these findings are confirmed in larger studies, PGA-paclitaxel could be used as a potential gender-specific first-line therapy to treat women with NSCLC.

In addition to lysosomally-cleavable peptide linkers, $\mathrm{pH}$-sensitive cis-aconityl, hydrazone and acetal linkages that respond to changes in intracellular $\mathrm{pH}$ have also been used [115]. They can be hydrolyzed under the local acidic $\mathrm{pH}$ (6.5-4) within endosomal and lysosomal vesicles [136]. As such, $\mathrm{pH}$-sensitive [137-140] or reduction-specific [141, 142] nanoparticle formulations have been designed to facilitate the intracellular delivery of active components. Once low molecular weight drugs are released in the endosome, they are free to escape the intracellular vesicles by diffusion. However, for high molecular weight or 
charged compounds (e.g., proteins or nucleic acids), passive diffusion through the membrane is difficult and the formulation needs to further provide endosome-disruptive properties to allow for intracytosolic delivery.

Considerable effort has been made to design various types of endosomolytic formulations, especially for the delivery of siRNA and other therapeutic nucleic acids. siRNA must escape from endosome compartments before endosomal/lysosomal degradation occurs in order to exert their gene silencing activity. A wide range of delivery systems have been developed, including dendrimers, liposomes, cationic lipid-like compounds (lipidoids), cyclodextrin, polyethyleneimine (PEI) and others, to facilitate endosomal escape and ensure cytosolic delivery of the therapeutics. In these systems, membrane-disruptive properties can be obtained by using proteins and peptides [143, 144], polymers [145, 146] or simply by incorporating a high number of ionisable amine groups to exploit the proton sponge effect [117]. Figure 8 illustrates the mechanisms of the proton sponge effect, in which nucleic acids are released from polyamine-containing nanoparticles in acidic endosomes. The key to understanding the proton pump hypothesis is the lysosomal proton pump (v-ATPase), which is responsible for acidification of the lysosomal compartment. Within acidifying lysosomal compartments, unsaturated amines on the nanoparticle surface are capable of sequestering protons that are supplied by the proton pump, continuing pump activity and leading to the retention of one $\mathrm{Cl}$ - anion and one water molecule for each proton that enters the lysosome. Ultimately, this process causes lysosomal swelling and rupture, leading to siRNA-loaded particle deposition in the cytoplasm [20].

Finally, increasing attention has been focused on the targeting of therapeutic agents to specific organelles. This can be achieved by attaching subcellular targeting ligands on the surface of nanomaterials to redirect their accumulation to desired compartments. For instance, Niemann-Pick type A and B are rare genetic LSDs associated with a deficiency of acid sphingomyelinase (ASM), a single enzyme required for the metabolism of lipids, glycoproteins or mucopolysaccharides [147]. A recent study demonstrated that the specific delivery of recombinant ASM to lysosomes by nanocarriers coated with antibody against intercellular adhesion molecule-1 (ICAM-1) could alleviate lysosomal lipid accumulation and improve the efficacy of enzyme replacement therapy [147].

2.3.2 Considerations for personalized medicine-The utilization of intracellular enzymes to trigger the therapeutic activity of nanoconstructs has considerable implications for personalized medicine. As differences in enzyme expression between individuals and pathologies are expected, the sophisticated systems described above might prove more beneficial in a certain subset of patient populations. For example, if the effect of genderspecific cathepsin B expression on the efficacy of PGA-paclitaxel is further confirmed in clinical trials, the appeal of the drug conjugate to treat women-specific cancer types (e.g., ovarian, breast) will certainly be strengthened. More generally, the linkers that can be cleaved by an intracellular protease of interest (e.g., Gly-Phe-Leu-Gly linker) might turn out to be very useful for the design of future drug delivery systems to treat patients overexpressing the target proteases.

The development of drug delivery systems which can effectively deliver their payload inside the cells is also crucial for the future of nucleic acid-based therapies. These therapies hold great promises as treatment and prevention methods for various diseases. For example, successful delivery of siRNA could inhibit the expression of MDR transporters and may restore tumors' chemosensitivity to treatment [148, 149]. In this context, the combination of conventional chemotherapeutics with siRNA-based therapeutics represents a promising therapy for patients with chemoresistance malignancies. 


\section{Engineered nanomaterials for personalized medicine applications}

Nanomaterials have evolved significantly over the last few years and nanomedicine has brought unprecedented advances in the diagnosis, imaging and treatment of a variety of diseases. Presently, nearly 250 nano-sized products exist in various stages of development, including nanomaterials with different compositions, physicochemical characteristics, surface functionality and geometry [150]. The following section will explore some examples of the applications of nanomaterials relevant to personalized medicine and the associated design features based on an understanding of nano-bio interactions.

\subsection{Ex vivo diagnostics}

The identification of biomarkers represents the first step in attaining an individually tailored medicine. Biomarkers could be mutant genes, RNAs, proteins, lipids or metabolites that are associated with a specific pathological stage or clinical outcome. Molecular profiling studies on biomarker discoveries have shown that gene expression patterns can be used to identify cancer classification, yielding new insights into tumor pathology such as stage, grade, clinical course and response to treatment [151]. Alizadeh et al. were the first to report the correlation between gene expression patterns and clinically distinct subtypes of cancer based on their study of diffuse large B-cell lymphoma [152]. The concept of a specific molecular profile for each patient's tumor was later validated $[153,154]$. By linking biomarkers with cancer behavior, it is possible to improve diagnosis, assess response to treatment and evaluate progression of cancer based on each patient's molecular profile [155].

The enhanced interactions that occur between nanomaterials and biomacromolecules (e.g., proteins and nucleic acids) markedly improve the sensitivities of current detection methods. Nanomaterial surfaces can be tailored to selectively bind biomarkers and sequester them for subsequent high-sensitivity proteomic tests [156]. For example, nanoparticles containing DNA sequences complementary to messenger RNAs of biomarker genes can be used as simple and semi-quantitative beacons for the detection of the expression patterns of biomarkers in a single cell [157]. A bio-barcode assay has been recently developed based on oligonucleotide modified gold nanoparticles for high-throughput detection of nucleic acid and protein targets [15]. This approach utilizes gold nanoparticles functionalized with oligonucleotides and antibodies to target either a patient's DNA or a protein sample and can detect multiple markers with high accuracy (95\%). This nanoparticle-based bio-barcode assay has extraordinarily high sensitivity $\left(10^{-18} \mathrm{M}\right)$ similar to that of PCR-based assays but without the need for lengthy amplification procedures [14, 15]. Furthermore, this approach does not suffer from the problems often associated with conventional fluorescent probes for microarray labeling, such as photobleaching (loss of signal after exposure to light), which opens a new avenue for developing highly selective panel assays for early detection of a wide range of diseases. This technology has been approved by the FDA for genetic screening to determine drug sensitivity and to detect genetic mutations. It is currently being validated for the detection of proteins found in prostate cancer, ovarian cancer, and Alzheimer's disease [16].

Likewise, the simultaneous use of nanomaterials with different ligands can allow concurrent detection and precise profiling of the epitopes present in cell specimens. Yezhelyev et al. demonstrated the detection and quantification of multiple biomarkers in human breast cancer cells and biopsies using QDs conjugated with primary antibodies against HER2, ER, PR, EGFR and mTOR [158]. The parallel evaluations of three specimens revealed distinct molecular profiles: one tumor biopsy over-expressed EGFR, another ER and PR, and the third one ER and HER2. This high throughput ex vivo screening analysis could be used to identify the molecular signatures of an individual patient's tumor, and to correlate a panel of 
cancer biomarkers with the clinically distinct subset of biomarkers present in the patient's tumor.

Nanomaterials can also be used to harvest disease-relevant biomarkers in the sample for early detection. Luchini et al. used Poly(N-isopropylacrylamide) hydrogel nanoparticles to harvest and concentrate low molecular weight (LMW) biomarkers (e.g., proteins and metabolites) from biological fluids via electrostatic interactions [159]. The hydrogel nanoparticles possessed defined porosity and negatively- and positively-charged groups for a rapid one-step sequestration and concentration of the ionized LMW fractions from complex serum molecules. The captured peptides or proteins were protected from further enzymatic degradation and were readily extracted from the particles by electrophoresis. When using the nanoporous sieves presented in this study, the proteins are denatured when eluted out of particles and then analyzed by MS for biomarker discovery. The denaturation step may hinder subsequent applications that require the analytes to be in their native state (e.g., immunoassays, enzymatic assays). Therefore, it is necessary to develop novel nanoparticles which preserve the conformational integrity of the isolated proteins. Combined with current proteomic technologies, these nanoparticles provide enormous enhancement of rare biomarkers associated with disease.

\subsection{In vivo imaging}

In recent years, several medical diagnostic technologies have been developed for clinical imaging and detection, including fluorescence imaging, positron emission tomography (PET), single-photon-emission computer tomography (SPET), and magnetic resonance imaging (MRI). These methods require injection of fluorescent trackers, radionuclides or contrast agents. The development of contrast agents able to target specific molecules could advance the molecular characterization of disease, from the identification of diseaseassociated molecular pathways to the clinical monitoring of relevant biomarkers before and after treatment [5]. Nanomaterials have been explored as platforms for the development of novel contrast agents because they are easily functionalized, possess high contrast, and have tunable physicochemical properties [5].

Various formulations of superparamagnetic iron oxide nanoparticles (SPIONs) are approved or are under clinical investigation for imaging. A key advantage of SPIONs in comparison to other inorganic or heavy metal-based MRI contrast agents is their innocuity. Particles can be degraded to iron and iron oxides molecules that are metabolized, stored in intracellular pools as ferritin, and incorporated into hemoglobin [160]. Administration of 100-200 mg iron/ $\mathrm{kg}$ in rodent models elicited no detectable side effects $[160,161]$, a dose well above that used for MRI procedures ( $<5 \mathrm{mg} / \mathrm{kg}$ ). Ferumoxides (Feridex I.V.®) and ferucarbotan (Resovist ${ }^{\circledR}$ ) are clinically approved as the first generation SPIONs and are suitable for T2and $\mathrm{T} 2 *$-weighted imaging. These contrast agents rely on passive targeting strategies to detect and evaluate lesions of the liver associated with an alteration in the MPS [162]. Their distinctive in vivo behavior dictates their utility in the clinic: ferumoxides, administered via slow infusion, for the detection of small focal lesions with high accuracy during delayed phase imaging [163] and ferocarbotan, which can be administered as a rapid bolus, to produce higher liver-to-tumor contrast during dynamic imaging [164]. Two other SPIONs formulations are currently in clinical trials as contrast agents for MR angiography (MRA). Supravist (Ferucarbotran, a T1-weighted reformulation of Resovist) and VSOP-C184 (7-nm, citrate-coated SPION formulation) have generated first-class images comparable to those using gadolinium $(\mathrm{Gd})$ based agents but with favorable safety, tolerability, and efficacy data [165-167]. These nanoparticle-based MRA agents will likely play an important role in advancing angiography as imaging modality for personalized medicine due to their advantages of long plasma half-life and ultra-small sizes that facilitate the detection of small vessels with slow and/or complex flow [165, 168]. SPIONs are now being developed to 
track cell movement in vivo following transplantation with the long-term goal of developing and monitoring personalized cell-based therapies [169].

For similar applications and as an alternative approach to the use of MRI, others have utilized QDs as probes for high resolution molecular imaging of cellular components and for tracking a cell's activities and movements inside the body [170,171]. With the capability of single-cell detection, these nanomaterials enable the real-time characterization of properties of certain cancer cells that distinguish them from closely related non-pathogenic cells.

Since targeted cancer treatments are selected on the basis of the expression patterns of specific biomarkers, there is an urgent need for detecting and monitoring the changes in biomarker expression in situ in a non-invasive manner. Nanoparticles are in development to maximize the specificity of contrast agents by exploiting receptor-ligand interactions. Targeted nanoparticles are able to accumulate at sites where the molecular target is expressed, increasing the local concentration of contrast agents.

One example is the ${ }^{18} \mathrm{~F}$-labeled ABY-025 affibody, a compact three-helix bundle that binds HER-2 $[5,172]$. When tested in animals, the ${ }^{18} \mathrm{~F}$-labeled ABY- 025 was able to directly assess HER-2 expression in vivo using PET and monitor changes in receptor expression in response to therapeutic interventions [172]. Lee and colleagues also reported that herceptinconjugated magnetic nanoparticles that target HER-2 could significantly enhance MR sensitivity compared with currently available probes, enabling the detection of a tumor mass as small as $50 \mathrm{mg}$ [173]. The correlation of the signal observed by non-invasive imaging modalities with receptor expression could be utilized to perform follow-up studies without the need for biopsies to evaluate treatment efficacy and direct therapy tailoring.

In the near future, in vivo imaging techniques using nanomaterials will go beyond the field of oncology. Monocrystalline iron oxide particles functionalized with anti-myosin Fab fragments are in preclinical development to detect myocardial infarcts [174]. Similarly, combination approaches using two or more imaging modalities are particularly appealing. Cross-linked iron oxide nanoparticles (CLION) activated by proteases were prepared by encapsulating iron oxide nanoparticles within polymer-Cy5.5 conjugates, combining fluorescence and MRI imaging to assess the enzymatic activity in plaques [175-178]. In this system, the fluorescence of the multiple Cy5.5 molecules was quenched until the lysinelysine bonds were cleaved by cathepsin B, which is upregulated in atherosclerotic lesions. The CLION developed initially for tomography was also able to image vulnerable plaques and infarcted lesions. Other multi-modal nanoparticle-based contrast agents include fluorescently labeled gadolinium-conjugated gold nanoparticles [179] and paramagnetic lipid-coated QDs [180].

\subsection{Theranostic nanoparticles}

Theranostic nanoparticles integrate molecular imaging and drug delivery, allowing the imaging of therapeutic delivery as well as follow-up studies to assess treatment efficacy [181-183]. Theranostic nanoparticles can serve as useful tools to explore the fundamental process of drug release after cellular internalization of nanoparticles, which could provide key insights into the rational design of targeted nanocarriers for personalized treatment.

For example, a smart core-shell QD platform, namely QD-aptamer (doxorubicin), was engineered to sense drug release (Figure 9) [183]. A10 RNA aptamer was used to recognize the extracellular domain of PSMA. The intercalation of doxorubicin within the doublestranded "GC" dinucleotide segment of the A10 aptamer on the surface of QDs resulted in quenching of both QD and doxorubicin fluorescence ("OFF" state). Upon receptor-mediated endocytosis of targeted QD conjugates into PSMA-expressing prostate cancer cells, the 
released doxorubicin induced the recovery of fluorescence from both the QDs and doxorubicin ("ON" state). This system allowed sensing of the intracellular release of doxorubicin and enabled the synchronous fluorescent localization and killing of cancer cells.

Another elegant design is the drug-containing paramagnetic nanoparticles targeted to various atherosclerotic plaque lesions components including the av $\beta 3$ integrin [184], fibrin [185], and collagen type III [186], allowing both targeted MR imaging and drug delivery. Animal studies were performed using av $\beta 3$-targeted nanoparticles containing the antiangiogenesis drug fumagillin repeatedly administered to atherosclerotic rabbits [184]. The results demonstrated that nanoparticle accumulation enabled imaging of the atherosclerotic lesion and generated an anti-angiogenic effect. Advances in this field will pave the way for detecting disease, targeting therapies, and assessing response with one single nanoparticle agent.

\subsection{Targeted therapies}

One of the major avenues of personalized nanomedicine is the development of delivery platforms that can specifically target diseased tissues (i.e., tumor) [187]. In theory, drug targeting would not only ensure a more effective treatment of the target tissue, but also permit a much lower overall dose to be administered than conventional drug delivery, reducing adverse side effects and increasing patient compliance. Two approaches, both passive and active targeting, have been utilized to home nanoparticles to active sites in disease conditions.

Passive targeting takes advantage of the inherent biophysicochemical properties of the nanoparticles (size, shape, charge and flexibility etc.). This phenomenon is most often associated with EPR effects in tumors. A recent in vivo breast cancer study in rodents showed that the passive targeting approach can be used to personalize treatment [188]. Individualized therapy in its simplest form could be achieved by studying the intratumoral accumulation of iodine-containing liposomes by X-ray tomography to predict the deposition of therapeutic doxorubicin-loaded liposomes in the diseased tissue [188]. If tumor accumulation is found to correlate with the patient's susceptibility to treatment, this approach could be used to identify individuals with lesions possessing leaky vasculature and who would benefit the most from nanosized formulation.

Actively targeted personalized therapies involve surface modification of drug carriers with ligands such as antibodies, peptides, aptamers, and small molecules that specifically bind to tissues of interest. The drug can then be delivered to the target cells through receptormediated internalizing interactions as presented in section 2.2 and 2.3. The binding targets of the modified nanocarriers include differentially overexpressed receptors/antigens on the plasma membrane of disease cells and the differentially overexpressed extra-cellular matrix proteins in diseased tissues. For instance, a peptide-conjugated nanoparticle was shown to target the vascular basement membrane exposed on injured vasculature [189]. The C-11 peptide decorating the nanoparticles showed high affinity for collagen IV, which represents $50 \%$ of the vascular basement membrane. This targeted nanoparticle platform holds particular promise for treatments of targeted blood vessel walls such as catheter or stentinduced cardiovascular injuries.

Intracellular organelles can also be targeted. Direct DNA delivery to the mitochondrial matrix has been suggested for the treatment of genetic diseases associated with mitochondrial genome defects [190]. Lee et al. conjugated the mitochondrial leader peptide, a peptide derived from the nucleocytosol-expressed but mitochondria-localized ornithine transcarbamylase, to polyethylenimine using a disulfide bond to render the resultant PEIMLP conjugates mitochondriotropic [190]. In vitro delivery tests of rhodamine-labeled 
DNA into living cells demonstrated that PEI-MLP/DNA complexes were localized at mitochondrial sites. The data suggested that PEI-MLP can deliver DNA to the mitochondrial sites and may be useful for the development of direct mitochondrial gene therapy.

\subsection{Combination therapies}

The combination of multiple therapeutic agents in a single nanocarrier has been proposed as an alternative approach to increase the efficacy of anticancer treatments through synergistic interactions while mitigating drug resistance [191]. As a proof of concept, Kolishetti et al. developed a targeted therapeutic nanoparticle system for co-delivery of cisplatin and docetaxel, two drugs with different metabolic targets, to prostate cancer cells [192]. In this approach, a Pt(IV) cisplatin prodrug-polymer conjugate was blended with PLGA-PEG and docetaxel to form nanoparticles (Figure 10) [192]. The dual-drug encapsulated nanoparticles were then conjugated with the A10 aptamer to target PSMA overexpressing cancer cells. In vitro studies demonstrated that the aptamer targeted, dual-drug loaded nanoparticles were 5 to 10 times more cytotoxic than respective single drug encapsulating nanoparticles.

The release of multiple payloads can also be tailored to enhance efficacy. Sengupta et al. synthesized a biphasic "nanocell" with a lipid layer containing combretastatin and a hydrophobic core containing PLGA-doxorubicin conjugates [193]. This construct enabled temporal release of the two drugs: combrestatin was released first to collapse the blood vessels and trap the particles inside the tumor, followed by the release of doxorubicin to kill the tumor cells focally without being diluted by the blood circulation. The polymeric nanocell was compared with liposomes co-encapsulating combretastatin and doxorubicin, which lack the differential drug release kinetics. In murine models bearing Lewis lung carcinoma and B16/F10 melanoma, the nanocell platform resulted in better tumor reduction, longer median survival time, and lower systemic toxicity. This study demonstrated that sequential delivery and scheduling of combinatorial drugs are important parameters that influence drug synergism and side effects.

Finally, combination strategies are particularly appealing in the case of siRNA delivery where the knockdown of specific genes can lead to tremendous improvement in the efficiency of drugs. For instance, MDR-1 gene silencing and paclitaxel co-therapy in PLGA nanoparticles was shown to significantly contribute in overcoming tumor multidrug resistance in vivo [194]. Taken together, the development of combination nanotherapeutic strategies that combine gene silencing and drug delivery could provide a more potent therapeutic effect, especially in refractory tumors.

Research on the development of combinational therapies is on the rise. However, this area will benefit from further investigations involving: (1) the discovery of efficacious molecular targets in cancer cells and better understanding of drug activity in these cells; (2) understanding the pharmacokinetics of different drugs by simultaneously delivering multiple therapeutic agents to the target site; (3) the demonstration of the contribution of each component of the combination to the treatment effect; (4) the development of nanocarriers that allow for precisely-controlled loading and release of two or more drugs with variable properties; and (5) the evaluation of responses to treatment among patients following the use of combination therapies.

\section{Challenges with nanomaterials for personalized nanomedicine}

\subsection{Toxicity of nanomaterials}

The uncertain health hazard potential of nanomaterials is probably the most significant hurdle for regulatory approval and commercialization of nanomedical products [195]. The unique physical and chemical properties of nanomaterials (i.e. small size, increased 
reactivity, high surface-to-volume ratio, etc.) while are likely to provide health benefits, may also be associated with deleterious effects on cells and tissues [187, 196]. Nanomaterials have dimensions similar to organelles found in the cell and have the potential to interfere with vital cellular functions, resulting in potential toxicity [197]. While engineered nanomaterials offer improved half-life circulation, this implies that the time required for clearance of loaded drug will also be prolonged. Accordingly, some nanoparticles may be retained in the body not only for days, but potentially for years. Some nanomaterials such as metal nanoparticles, metal oxide nanoparticles, QDs, fullerenes and fibrous nanomaterials were found to induce chromosomal fragmentation, DNA strand breakages, point mutations, oxidative DNA adducts and alterations in gene expression [198], sometimes even through cellular barriers [199]. In these cases, the safety profile becomes a major concern. Although there have been no reported examples of clinical toxicity due to nanomaterials thus far, early studies indicate that nanomaterials could initiate adverse biological interactions that can lead to toxicological outcomes [200]. Since the mechanisms and severity of nanotoxicity are not fully predictable or testable with current toxicological methods, the toxicity of nanomaterials is rapidly emerging as an important area of tangential study in the nanomedicine research field.

There are many different factors to consider when designing nanomaterials and an understanding of how different parameters affect toxicity can aid in designing safer nanomaterials for medical applications. Some important parameters to consider include size, shape, surface area, charge, state of aggregation, crystallinity, and the potential to generate reactive oxygen species (ROS) [200]. Size is a significant factor and can influence the distribution and toxicity of a material. Studies with gold nanoparticles (AuNPs) in four different cell lines demonstrated that both toxicity and the mechanism of cell death were size-dependent [201]. $1.4 \mathrm{~nm}$ AuNPs were 60-fold more toxic than $15 \mathrm{~nm}$ AuNPs and cell death from $1.4 \mathrm{~nm}$ AuNPs was due to necrosis while $1.2 \mathrm{~nm}$ AuNPs caused apoptosis of the cells [201]. The toxicity of the $1.4 \mathrm{~nm}$ AuNPs was due to the ability to intercalate with DNA while AuNPs of larger sizes were unable to intercalate with the DNA [202]. Size can affect both the distribution within the body as well as the distribution within a cell [203, 204]. Studies of QDs in macrophages have shown that QD size influences subcellular trafficking, with the smallest QDs able to target histones in the cell nucleus [204]. Composition is another factor that influences the toxicity of nanomaterials. QDs may create a health hazard due to toxic heavy metal elements such as cadmium that are incorporated into the QDs [205]. It may, however, be possible to reduce the potential toxicity of nanomaterials such as QDs by adding a coating or nanoshell [206].

Carbon nanotubes (CNTs) are a nanomaterial that has great potential in various medical applications. However, concerns have emerged over its toxicity due to its shape, which resembles asbestos fibers [207]. Longer CNTs have been shown to act like indigestible fibers that lead to frustrated phagocytosis and granuloma formation [208]. Studies in mice have shown that frustrated phagocytosis can lead to massive release of oxygen radicals by immune cells, which can result in chronic granulomatous inflammation and potentially mesothelioma if the CNTs are in the pleural cavity or peritoneum [209]. CNTs can cause mutagenic effects through the generation of inflammation and direct interaction with components of the cell. Exposure of mice to CNTs by inhalation increased the rate of mutation of the K-ras gene locus in the lung, with the mutations occurring during times of maximum inflammation in the tissue [210]. CNTs can also interact directly with the cellular cytoskeleton, including the microtubule system during the formation of the mitotic spindle apparatus, leading to aberrant cell division [211].

Nanomaterials such as titanium dioxide can cause toxicity based on crystalline structure. Cytotoxic studies showed that the anatase form of titanium dioxide was 100 times more 
toxic than the rutile form, and that the toxicity correlated with the generation of ROS under UV light [212]. Oxidative stress and the generation of ROS is a key injury mechanism that promotes inflammation and atherogenesis, resulting in adverse health events [213, 214]. The surface composition also plays a role in nanomaterial toxicity. Discontinuous crystal planes and material defects can act as sites for ROS generation [200]. The presence of transition metals or organic chemicals on the surface of nanomaterials can also result in oxygen radical formation and oxidative stress [215].

The degradability of a nanomaterial is another important parameter to consider for toxicity. If nondegradable nanomaterials have no mechanism of clearance from the body, they can accumulate in organs and cells and exert toxic effects. Injectable gold compounds have been used for the treatment of rheumatoid arthritis and the accumulation of gold compounds in the body over time may cause toxic effects in patients [216]. However, biodegradable materials may also cause toxic effects if the degraded components of the material are toxic [217].

In addition, the nanomaterial charge is a significant contributor to the toxicity of the material. Increased in vitro cytotoxicity and in vivo pulmonary toxicity has been observed for cationic polystyrene nanospheres when compared with anionic or neutral polystyrene $[218,219]$. Interestingly, the mechanism of toxicity for cationic nanospheres was dependent on the cell type and uptake mechanism [219]. In macrophages, particles entered the cell through phagosomes and caused lysosomal rupture due to the proton sponge effect. Upon entry into the cytosol, the particles caused an increase in $\mathrm{Ca}^{2+}$ uptake by mitochondria and oxidative stress, leading to apoptosis. In epithelial cells, cationic particles entered through caveolae. The particles also induced an increase in mitochondrial $\mathrm{Ca}^{2+}$ uptake and oxidative stress, but cell death was by necrosis.

As new nanomaterials are developed, it is important to consider potential mechanisms of toxicity. Nanomaterials have the increased potential to cross biological barriers and obtain access to tissues and cells as a result of their physicochemical properties. As novel properties are introduced into nanomaterials resulting in new interactions with biological systems, it is possible that new mechanisms of injury and toxicological paradigms might emerge [200]. A further understanding of how nanomaterials interact with biological systems may provide better methods to engineer nanomaterials to minimize toxicity [20].

\subsection{Mass transport}

Efficient delivery of nanotherapeutics is another challenge encountered in regards to nanomaterials. The small size of nanoparticles may result in acceleration or delay in their intended action. They may also accumulate non-specifically in certain tissues after administration. Enormous efforts have been expended towards achieving targeted delivery through modification of nanoparticles with antibodies, small molecules, aptamers and/or peptides. However, the biodistribution of nanotherapeutical agents is primarily governed by their ability to negotiate through biological barriers including the mononuclear phagocyte system (MPS), endothelial/epithelial membranes, complex networks of blood vessels, and abnormal blood flow. In addition, drug delivery is further inhibited by barriers such as enzymatic degradation and molecular/ionic efflux pumps that expel drugs from target cells. A full understanding of the interactions between nanomaterials and biological systems will open the door to rational design of nanomedicines and hence improve their biodistribution.

\subsection{Complexity of nanopharmaceuticals, characterization, stability and storage}

To design therapeutics and diagnostics that are functional for personalized use, multiple components will be integrated into a single nanomaterial, requiring multiple steps such as 
chemical synthesis, formulation and purification. Those procedures will inevitably lower the yield and increase the production cost. In addition, scale-up and manufacturing under current good manufacturing practice (cGMP) will be challenging. In general, multifunctional nanotherapeutics have more variables within their physicochemical properties, which make it more difficult to predict the fate and action after administration. The characterization of nanotherapeutic agents also poses a challenge to manufacturers as well as regulators in terms of chemical, physical, magnetic, optical and biological properties. It would be difficult to monitor a wide range of physicochemical parameters including composition, structure, shape, size, size distribution, concentration, agglomeration, surface functionality, porosity, surface area, surface charge, and surface specification after nanotherapeutic agents are administered.

Stability and storage are also hurdles that must be addressed for clinical practice. For example, biodegradable polymers have been widely used as nanotherapeutic carriers. Depending on their chemical and morphological properties, a polymer will start degrading after nanoparticle formulation in aqueous/organic solvents, which usually results in a change in physicochemical properties (such as agglomeration, particle size, surface charge, drug loading, drug release profile), and can in turn affect the performance in vivo. As such, storage conditions may be critical to the shelf life of nanotherapeutics. For example, the measurement result of nanoparticle size, surface charge, polymer degradation rate and drug release profile may be quite different when nanotherapeutics are stored in deionized water, as opposed to phosphate buffered saline (PBS) or human blood serum.

\subsection{Limitations and obstacles of personalized nanomedicine}

While personalized nanomedicine holds much promise, there are also many challenges associated with it that need to be overcome in order for it to reach its full potential. Manipulating materials at the nanoscale level is difficult and complex due to novel nanoscale interactions, forces and effects that can complicate the reliability, predictability and utility of nanomedical products. Moreover, the potential risks of nanomedicine products and the uncertainties associated with those risks make it difficult to design and obtain consent in clinical trials to assess the clinical utility of such products.

Regulatory approval of nanomedicine products may present another major obstacle. Personalized treatment strategies are inherently not designed to be safe and efficacious for a population, but rather for an individual. Due to the complexity and differences among individual patients in terms of therapeutic response, clinical outcome, genetic profile and many other factors, it is inconceivable to evaluate and approve an exponentially large combinatorial library of possible nanoparticle configurations with various sizes, shapes, surface modifications and therapeutic payloads, especially when considering the long time and high cost associated with the development of an average therapeutic. On the other hand, as the nanomaterials involved in personalized medical applications become more advanced and multifunctional, they may increasingly challenge and eventually invalidate traditional regulatory categories and criteria. Thus, regulatory reform is necessary to facilitate the translation of nano-based medical products into clinical use. It will be critical for the Food and Drug Administration (FDA) to make adjustments and additional requirements to provide predictable and well-defined evaluation pathways for nanomedicine products, and to adapt regulatory requirements when appropriate to keep pace with rapidly emerging nanomaterials and nanotechnologies.

The incorporation of nanomaterials and nanotechnology into personalized medicine also brings up ethical issues. Nanodiagnostics and genetic testing offer the opportunity to collect more personal data on patients than ever before [220]. In particular, the use of point-of-care nanodevices that may bypass a health care professional will have a large impact on mass 
collection of personal data. This large volume of molecular-level data collected by such nanodevices will challenge the health care system in terms of storage and handling as well as privacy issues, and may raise questions for patients who will receive a torrent of medical information that will inevitably contain false positive and other misleading data [187].

The advances in nanomaterials and nanobiotechnology will play an important role in the development of cutting-edge diagnostic and therapeutic tools, which are an essential component of personalized medicine. While nanomedicine products face safety, scientific, regulatory and ethical issues, personalized medicine also encounters challenges and obstacles. A major obstacle with personalized approaches such as genetic testing is heterogeneity. A recent study demonstrated that a tumor's genetic makeup can vary significantly within a single tumor [221]. The study showed that, within a single tumor, about $2 / 3$ of the mutations found in a single biopsy was not uniformly detected throughout all the sampled regions of the same patient's tumors. These results elucidated that a single biopsy cannot be considered representative of the landscape of genetic abnormalities in a tumor and that current practices may miss important genetic mutations that could affect the treatment of the disease [222]. Moreover, there were significant differences between mutations in the original tumor and the site of metastasis. The tumor discovered at diagnosis may be very different from the tumor that is growing or exposed to different treatments. However, getting additional biopsies from patients at different stages could be costly and inconvenient for patients. These findings represent a significant challenge for personalized medicine, as the use of genetic testing to direct therapy may be more complex than currently thought.

\subsection{Economic considerations}

The economical conundrums behind the advance of personalized nanomedicine are intricate. On the one hand, given the important resources devoted to the development of complex nanomaterial systems, the choice to focus only on the treatment of a subset of the population (i.e., HER-2 positive breast cancer patients) might be a difficult one to make. The aforementioned risks and challenges associated with the design of nanomaterial remain similar whether it is to treat all patients suffering from cancer or just a cohort showing a specific mutation. Therefore, the financial gain-to-risk ratio strongly leans towards applications which benefit larger populations. On the other hand, the proof of efficacy needed to obtain regulatory approval might be easier to obtain with a system rationally designed for a specific subpopulation where the prognosis with standard treatment is particularly grim. The evaluation of therapeutic candidates in patients that are more likely to benefit from it might speed up clinical trials and facilitate regulatory approval of the nanomaterial.

In this context, what makes nanomaterials remarkably appealing are their versatility and the ability to transfer the efforts dedicated to the development of one platform to other applications. The example of the CLION system, where the imaging platform was translated from oncology to cardiovascular applications was mentioned in section 3.2 [175-178], but others also exist. For example, liposomes similar to the commercially-available doxorubicin liposomal formulations were recently proposed to act as scavenging nanomaterials for drug detoxification [223, 224]. Similarly, 2-hydroxypropyl- $\beta$-cyclodextrin, an excipient which forms nanosized complexes with multiple drugs, was shown to overcome cholesterol metabolism dysfunction in Niemann-Pick Type C [225, 226]. It was approved in 2011 for the intravenous and intrathecal treatment of this very rare LSD.

Finally, the development of treatments for orphan or "niche" diseases might provide attractive entryways to the clinic for nanomaterials. The favorable benefit-to-risk ratio expressly encountered in disorders for which no current treatment exist can prove an 
efficient way of showing the feasibility of an approach as well as the tolerability and safety of a novel material. In this perspective, scientists at the Children's Hospital of Philadelphia have invested tremendous efforts in developing an adenovirus-based treatment for Leber Congenital Amaurosis (LCA), a very rare degenerative disease which irremediably leads to blindness [227-229]. This gene delivery vector, which is now in phase II/III for LCA, was developed in parallel with an analogous formulation containing encoding DNA for the human coagulation factor IX, for the treatment of hemophilia B [230]. These examples, showcasing the versatility of drug delivery systems, offer strong support to the future contribution of nanomedicine to personalized medicine.

\section{Conclusions}

In summary, the application of nanomaterials in the realm of medicine has demonstrated tremendous potential from early diagnosis of disease to the development of highly effective targeted therapeutics. As our understanding of health and disease become more refined at the molecular level, the potential of nanomaterials to address the biological complexities of diseases will increase. Likewise, opportunities to develop patient- and disease-specific therapeutics or diagnostic modalities will emerge.

Contemporary chemistry and material science enable the fabrication of a virtually infinite library of nanomaterials. In the near future, these materials will be engineered to efficiently optimize interactions with biological systems for a range of medical applications. For the purpose of targeted therapy and diagnostic imaging, nanocarriers should possess improved stability, extended circulation half-life, favorable biodistribution profiles, lower immunotoxicity as well as targeting to specific tissues, cells and subcellular organelles. Proper ligands will also be chosen based on differential expression of molecular markers on diseased cells to produce patient-specific nanomedicines. When used for detection and diagnosis, nanomaterials should be engineered to avoid non-specific protein absorption and specifically recognize the targets of interest with high affinity. In this context, an in-depth understanding and thorough investigation of how nanomaterials interact with biological structures is required. In order to promote the development of nanomedicines into clinically feasible therapies, there is an urgent need for complete characterization of nanomaterial interactions with biological milieus that drive possible toxicological responses. Medical products must be demonstrated to not only be effective but also safe before they are approved for patient use. Some experimental studies have indicated that engineered nanomaterials could exhibit unique toxicological properties in cell culture and in animal models that may not be predicted from the toxicological assessment of the bulk version of the same materials. To establish a database and appropriated standardized protocols for toxicity assessment, the mechanism of nanomaterial-induced toxicity must be fully explored and nanomaterials must be investigated in vitro and in vivo (e.g., absorption, distribution, metabolism, excretion and toxicological studies) on a particle-by-particle basis.

In parallel, the concept of personalized medicine is also particularly appealing from the perspective of optimizing treatments for an individual patient. Nevertheless, this is a nascent field that has yet to reach its full potential. A potential error may be to succumb to overenthusiasm and adopt personalized therapeutic practices without strong evidence that personalized treatment is superior to conventional approaches. Even in the field of antibodybased targeted anticancer treatments, which benefited from a head-start in individualized therapies, each clinical or genomic study brings new understanding of the intricate phenomena involved in treating the disease [231]. The understanding of all genomic components of complex diseases like cancer is still unraveling. One should therefore be careful before jumping to conclusions in identifying a particular biomarker as the new ubiquitous target that will eradicate the disease once and for all. 
Although significant challenges exist, including regulatory issues and scientific challenges associated with manufacturing nanomedical products, the development and deployment of personalized nanomedicines holds enormous promise for the future treatment of complex diseases. Some nanomedicine products are already in clinical trials, and many others are in various phases of preclinical development. Critical and rational assessment of clinical needs coupled with an improved understanding of physicochemical parameters of nanomaterials that define their effects on the biological system will foster the development of efficient and safe nanomedicine. It is therefore practical to envision a future translation of personalized nanomedicine to the bedside.

\section{Acknowledgments}

This work was supported by the National Institutes of Health (NIH) (grant CA151884), the National Heart, Lung, and Blood Institute, (NIH), through a Program of Excellence in Nanotechnology (PEN) Award, (Contract \#HHSN268201000045C) and the David Koch-Prostate Cancer Foundation Award in Nanotherapeutics. Dr. Xiaoyang Xu acknowledges postdoctoral support from an NIH National Research Service Award (NRSA) 1F32CA168163-01. Dr. Nicolas Bertrand acknowledges a post-doctoral fellowship from the Canadian Institutes of Health Research (CIHR). Dr. Farokhzad declares financial interests in BIND Biosciences, Selecta Biosciences and Blend Therapeutics. The rest of the authors declare no conflict of interest.

\section{References}

[1]. Ferrari M. Cancer nanotechnology: opportunities and challenges. Nat. Rev. Cancer. 2005; 5:161171. [PubMed: 15738981]

[2]. Jain KK. Role of nanobiotechnology in the development of personalized medicine. Nanomedicine (Lond). 2009; 4:249-252. [PubMed: 19331532]

[3]. Jain KK. Personalized medicine. Curr. Opin. Mol. Ther. 2002; 4:548-558. [PubMed: 12596356]

[4]. Vizirianakis IS. Nanomedicine and personalized medicine toward the application of pharmacotyping in clinical practice to improve drug-delivery outcomes. Nanomedicine. 2011; 7:11-17. [PubMed: 21094279]

[5]. Sakamoto JH, van de Ven AL, Godin B, Blanco E, Serda RE, Grattoni A, Ziemys A, Bouamrani A, Hu T, Ranganathan SI, De Rosa E, Martinez JO, Smid CA, Buchanan RM, Lee SY, Srinivasan S, Landry M, Meyn A, Tasciotti E, Liu X, Decuzzi P, Ferrari M. Enabling individualized therapy through nanotechnology. Pharmacol. Res. 2010; 62:57-89. [PubMed: 20045055]

[6]. Hrkach J, Von Hoff D, Ali MM, Andrianova E, Auer J, Campbell T, De Witt D, Figa M, Figueiredo M, Horhota A, Low S, McDonnell K, Peeke E, Retnarajan B, Sabnis A, Schnipper E, Song JJ, Song YH, Summa J, Tompsett D, Troiano G, Van Geen Hoven T, Wright J, Lorusso P, Kantoff PW, Bander NH, Sweeney C, Farokhzad OC, Langer R, Zale S. Preclinical Development and Clinical Translation of a PSMA-Targeted Docetaxel Nanoparticle with a Differentiated Pharmacological Profile. Sci. Transl. Med. 2012; 4:128ra139.

[7]. Barenholz Y. Doxil® — The first FDA-approved nano-drug: Lessons learned. J. Control. Release. 2012; 160:117-134. [PubMed: 22484195]

[8]. http://clinicaltrials.gov/ct2/show/NCT01455389

[9]. Hu CM, Zhang L, Aryal S, Cheung C, Fang RH, Zhang L. Erythrocyte membrane-camouflaged polymeric nanoparticles as a biomimetic delivery platform. P. Natl. Acad. Sci. USA. 2011; 108:10980-10985.

[10]. Fodor SP, Read JL, Pirrung MC, Stryer L, Lu AT, Solas D. Light-directed, spatially addressable parallel chemical synthesis. Science. 1991; 251:767-773. [PubMed: 1990438]

[11]. Demers LM, Ginger DS, Park SJ, Li Z, Chung SW, Mirkin CA. Direct patterning of modified oligonucleotides on metals and insulators by dip-pen nanolithography. Science. 2002; 296:18361838. [PubMed: 12052950]

[12]. Lee KB, Park SJ, Mirkin CA, Smith JC, Mrksich M. Protein nanoarrays generated by dip-pen nanolithography. Science. 2002; 295:1702-1705. [PubMed: 11834780] 
[13]. Lee KB, Lim JH, Mirkin CA. Protein nanostructures formed via direct-write dip-pen nanolithography. J. Am. Chem. Soc. 2003; 125:5588-5589. [PubMed: 12733870]

[14]. Nam JM, Thaxton CS, Mirkin CA. Nanoparticle-based bio-bar codes for the ultrasensitive detection of proteins. Science. 2003; 301:1884-1886. [PubMed: 14512622]

[15]. Kim BY, Rutka JT, Chan WC. Nanomedicine N. Engl. J. Med. 2012; 363:2434-2443.

[16]. Thaxton CS, Elghanian R, Thomas AD, Stoeva SI, Lee JS, Smith ND, Schaeffer AJ, Klocker H, Horninger W, Bartsch G, Mirkin CA. Nanoparticle-based bio-barcode assay redefines "undetectable" PSA and biochemical recurrence after radical prostatectomy. Proc. Natl. Acad. Sci. U. S. A. 2009; 106:18437-18442. [PubMed: 19841273]

[17]. Morigi V, Tocchio A, Bellavite Pellegrini C, Sakamoto JH, Arnone M, Tasciotti E. Nanotechnology in medicine: from inception to market domination. J. Drug Deliv. 2012; 2012 doi:10.1155/2012/389485.

[18]. Wagner V, Dullaart A, Bock AK, Zweck A. The emerging nanomedicine landscape. Nat. Biotechnol. 2006; 24:1211-1217. [PubMed: 17033654]

[19]. Harper S, Usenko C, Hutchison JE, Maddux BLS, Tanguay RL. In vivo biodistribution and toxicity depends on nanomaterial composition, size, surface functionalisation and route of exposure. J. Exp. Nanosci. 2008; 3:195-206.

[20]. Nel AE, Mädler L, Velegol D, Xia T, Hoek EMV, Somasundaran P, Klaessig F, Castranova V, Thompson M. Understanding biophysicochemical interactions at the nano-bio interface. Nat. Mater. 2009; 8:543-557. [PubMed: 19525947]

[21]. Lord MS, Foss M, Besenbacher F. Influence of nanoscale surface topography on protein adsorption and cellular response. Nano Today. 2010; 5:66-78.

[22]. Owens DE 3rd, Peppas NA. Opsonization, biodistribution, and pharmacokinetics of polymeric nanoparticles. Int. J. Pharm. 2006; 307:93-102. [PubMed: 16303268]

[23]. Bertrand N, Leroux JC. The journey of a drug carrier in the body: an anatomo-physiological perspective. J. Controlled Release. 2012; 161:152-163.

[24]. Moghimi SM, Hunter AC, Murray JC. Long-circulating and target-specific nanoparticles: theory to practice. Pharmacol. Rev. 2001; 53:283-318. [PubMed: 11356986]

[25]. Kutscher HL, Chao P, Deshmukh M, Singh Y, Hu P, Joseph L, Reimer DC, Stein S, Laskin DL, Sinko PJ. Threshold size for optimal passive pulmonary targeting and retention of rigid microparticles in rats. J. Controlled Release. 2010; 143:31-37.

[26]. Gref R, Luck M, Quellec P, Marchand M, Dellacherie E, Harnisch S, Blunk T, Muller RH. 'Stealth' corona-core nanoparticles surface modified by polyethylene glycol (PEG): influences of the corona (PEG chain length and surface density) and of the core composition on phagocytic uptake and plasma protein adsorption. Colloid Surfaces B. 2000; 18:301-313.

[27]. Peracchia MT, Harnisch S, Pinto-Alphandary H, Gulik A, Dedieu JC, Desmaele D, d'Angelo J, Muller RH, Couvreur P. Visualization of in vitro protein-rejecting properties of PEGylated stealth polycyanoacrylate nanoparticles. Biomaterials. 1999; 20:1269-1275. [PubMed: 10403044]

[28]. Bazile D, Prud'homme C, Bassoullet MT, Marlard M, Spenlehauer G, Veillard M. Stealth Me.PEG-PLA nanoparticles avoid uptake by the mononuclear phagocytes system. J. Pharm. Sci. 1995; 84:493-498. [PubMed: 7629743]

[29]. Peracchia MT, Fattal E, Desmaele D, Besnard M, Noel JP, Gomis JM, Appel M, d'Angelo J, Couvreur P. Stealth PEGylated polycyanoacrylate nanoparticles for intravenous administration and splenic targeting. J. Control Release. 1999; 60:121-128. [PubMed: 10370176]

[30]. Matsumura Y, Maeda H. A new concept for macromolecular therapeutics in cancer chemotherapy: mechanism of tumoritropic accumulation of proteins and the antitumor agent SMANCS. Cancer Res. 1986; 46:6387-6392. [PubMed: 2946403]

[31]. Spisak S, Tulassay Z, Molnar B, Guttman A. Protein microchips in biomedicine and biomarker discovery. Electrophoresis. 2007; 28:4261-4273. [PubMed: 17979160]

[32]. Johnson CJ, Zhukovsky N, Cass AE, Nagy JM. Proteomics nanotechnology and molecular diagnostics. Proteomics. 2008; 8:715-730. [PubMed: 18297650]

[33]. Vaisocherova H, Yang W, Zhang Z, Cao Z, Cheng G, Piliarik M, Homola J, Jiang S. Ultralow fouling and functionalizable surface chemistry based on a zwitterionic polymer enabling 
sensitive and specific protein detection in undiluted blood plasma. Anal. Chem. 2008; 80:78947901. [PubMed: 18808152]

[34]. Dalsin JL, Hu BH, Lee BP, Messersmith PB. Mussel adhesive protein mimetic polymers for the preparation of nonfouling surfaces. J. Am. Chem. Soc. 2003; 125:4253-4258. [PubMed: 12670247]

[35]. Bachmann MF, Jennings GT. Vaccine delivery: a matter of size, geometry, kinetics and molecular patterns. Nature Reviews: Immunology. 2010; 10:787-796.

[36]. Ishihara T, Takeda M, Sakamoto H, Kimoto A, Kobayashi C, Takasaki N, Yuki K, Tanaka K-I, Takenaka M, Igarashi R, Maeda T, Yamakawa N, Okamoto Y, Otsuka M, Ishida T, Kiwada H, Mizushima Y, Mizushima T. Accelerated blood clearance phenomenon upon repeated injection of PEG-modified PLA-nanoparticles. Pharm. Res. 2009; 26:2270-2279. [PubMed: 19633820]

[37]. Semple SC, Harasym TO, Clow KA, Ansell SM, Klimuk SK, Hope MJ. Immunogenicity and rapid blood clearance of liposomes containing polyethylene glycol-lipid conjugates and nucleic acid. J. Pharmacol. Exp. Ther. 2005; 312:1020-1026. [PubMed: 15525796]

[38]. Dams ETM, Laverman P, Oyen WJG, Storm G, Scherphof GL, Van der Meer JWM, Corstens FHM, Boerman OC. Accelerated blood clearance and altered biodistribution of repeated injections of sterically stabilized liposomes. J. Pharmacol. Exp. Ther. 2000; 292:1071-1079. [PubMed: 10688625]

[39]. Ishida T, Atobe K, Wang XY, Kiwada H. Accelerated blood clearance of PEGylated liposomes upon repeated injections: Effect of doxorubicin-encapsulation and high dose first injection. J. Controlled Release. 2006; 115:251-258.

[40]. Laverman P, Carstens MG, Boerman OC, Dams ETM, Oyen WJG, Van Rooijen N, Corstens FHM, Storm G. Factors affecting the accelerated blood clearance of polyethylene glycolliposomes upon repeated injection. J. Pharmacol. Exp. Ther. 2001; 298:607-612. [PubMed: 11454922]

[41]. Ishida T, Harada M, Wang XY, Ichihara M, Irimura K, Kiwada H. Accelerated blood clearance of PEGylated liposomes following preceding liposome injection: effects of lipid dose and PEG surface-density and chain length of the first-dose liposomes. J. Controlled Release. 2005; 105:305-317.

[42]. Koide H, Asai T, Hatanaka K, Urakami T, Ishii T, Kenjo E, Nishihara M, Yokoyama M, Ishida T, Kiwada H, Oku N. Particle-size dependent triggering of accelerated blood clearance phenomenon. Int. J. Pharm. 2008; 362:197-200. [PubMed: 18586076]

[43]. Szebeni J, Muggia F, Gabizon A, Barenholz Y. Activation of complement by therapeutic liposomes and other lipid excipient-based therapeutic products: Prediction and prevention. Adv. Drug Deliv. Rev. 2011; 63:1020-1030. [PubMed: 21787819]

[44]. Moghimi SM, Hamad I, Andresen TL, Jorgensen K, Szebeni J. Methylation of the phosphate oxygen moiety of phospholipid-methoxy(polyethylene glycol) conjugate prevents PEGylated liposome-mediated complement activation and anaphylatoxin production. Faseb J. 2006; 20:2591-2593. [PubMed: 17065229]

[45]. Garbuzenko O, Zalipsky S, Qazen M, Barenholz Y. Electrostatics of PEGylated micelles and liposomes containing charged and neutral lipopolymers. Langmuir. 2005; 21:2560-2568. [PubMed: 15752053]

[46]. Zalipsky, S.; Barenholz, Y. Liposome composition for reduction of liposome-induced complement activation. PCT Patent Application. (WO 2004/078121). 2004.

[47]. Chanan-Khan A, Szebeni J, Savay S, Liebes L, Rafique NM, Alving CR, Muggia FM. Complement activation following first exposure to pegylated liposomal doxorubicin (Doxilß): possible role in hypersensitivity reactions. Ann. Oncol. 2003; 14:1430-1437. [PubMed: 12954584]

[48]. Szebeni J. Complement activation-related pseudoallergy: a new class of drug-induced acute immune toxicity. Toxicology. 2005; 216:106-121. [PubMed: 16140450]

[49]. Ricklin D, Hajishengallis G, Yang K, Lambris JD. Complement: a key system for immune surveillance and homeostasis. Nat Immunol. 2010; 11:785-797. [PubMed: 20720586] 
[50]. Salvador-Morales C, Zhang L, Langer R, Farokhzad OC. Immunocompatibility properties of lipid-polymer hybrid nanoparticles with heterogeneous surface functional groups. Biomaterials. 2009; 30:2231-2240. [PubMed: 19167749]

[51]. Hamad I, Christy Hunter A, Rutt KJ, Liu Z, Dai H, Moein Moghimi S. Complement activation by PEGylated single-walled carbon nanotubes is independent of $\mathrm{C} 1 \mathrm{q}$ and alternative pathway turnover. Mol Immunol. 2008; 45:3797-3803. [PubMed: 18602161]

[52]. Hamad I, Al-Hanbali O, Hunter AC, Rutt KJ, Andresen TL, Moghimi SM. Distinct polymer architecture mediates switching of complement activation pathways at the nanosphere-serum interface: implications for stealth nanoparticle engineering. ACS Nano. 2010; 4:6629-6638. [PubMed: 21028845]

[53]. Moghimi SM, Andersen AJ, Hashemi SH, Lettiero B, Ahmadvand D, Hunter AC, Andresen TL, Hamad I, Szebeni J. Complement activation cascade triggered by PEG-PL engineered nanomedicines and carbon nanotubes: the challenges ahead. J Control Release. 2010; 146:175181. [PubMed: 20388529]

[54]. Salvador-Morales C, Flahaut E, Sim E, Sloan J, Green ML, Sim RB. Complement activation and protein adsorption by carbon nanotubes. Mol Immunol. 2006; 43:193-201. [PubMed: 16199256]

[55]. Chonn A, Cullis PR, Devine DV. the role of surface-charge in the activation of the classical and alternative pathways of complement by liposomes. Journal of Immunology. 1991; 146:42344241.

[56]. Rensen PC, Van Dijk MC, Havenaa EC, Bijsterbosch MK, Kar Krujit J, Van Berkel TJC. Selective liver targeting of antivirals by recombinant chylomicrons: A new therapeutic approach to hepatitis B. Nat. Med. 1995; 1:221-225. [PubMed: 7585037]

[57]. Michaelis K, Hoffman M, Dreis S, Herbert E, Alyautdin R, Michaelis M, Kreuter J, Langer K. Covalent linkage of apolipoprotein $\mathrm{E}$ to albumin nanoparticles strongly enhances drug transport into the brain. J. Pharmacol. Exp. Ther. 2006; 317:1246-1253. [PubMed: 16554356]

[58]. Kreuter J, Hekmatara T, Dreis S, Vogel T, Gelperina S, Langer K. Covalent attachment of apolipoprotein A-I and apolipoprotein B-100 to albumin nanoparticles enables drug transport into the brain. J. Controlled Release. 2007; 118:54-58.

[59]. Desai N, Trieu V, Damascelli B, Soon-Shiong P. SPARC Expression Correlates with Tumor Response to Albumin-Bound Paclitaxel in Head and Neck Cancer Patients. Transl. Oncol. 2009; 2:59-64. [PubMed: 19412420]

[60]. Sage H, Johnson C, Bornstein P. Characterization of a novel serum albumin-binding glycoprotein secreted by endothelial cells in culture. J. Biol. Chem. 1984; 259:3993-4007. [PubMed: 6368555]

[61]. Podhajcer OL, Benedetti LG, Girotti MR, Prada F, Salvatierra E, Llera AS. The role of the matricellular protein SPARC in the dynamic interaction between the tumor and the host. Cancer Metast. Rev. 2008; 27:691-705.

[62]. Desai NP, Trieu V, Hwang LY, Wu R, Soon-Shiong P, Gradishar WJ. Improved effectiveness of nanoparticle albumin-bound (nab) paclitaxel versus polysorbate-based docetaxel in multiple xenografts as a function of HER2 and SPARC status. Anticancer Drugs. 2008; 19:899-909. [PubMed: 18766004]

[63]. Shao H, Tang H, Salavaggione OE, Yu C, Hylander B, Tan W, Repasky E, Adjei AA, Dy GK. Improved response to nab-paclitaxel compared with cremophor-solubilized paclitaxel is independent of secreted protein acidic and rich in cysteine expression in non-small cell lung cancer. J. Thorac. Oncol. 2011; 6:998-1005. [PubMed: 21532503]

[64]. Desai N, Trieu V, Yao Z, Louie L, Ci S, Yang A, Tao C, De T, Beals B, Dykes D, Noker P, Yao R, Labao E, Hawkins M, Soon-Shiong P. Increased antitumor activity, intratumor paclitaxel concentrations, and endothelial cell transport of cremophor-free, albumin-bound paclitaxel, ABI-007, compared with cremophor-based paclitaxel. Clin. Cancer Res. 2006; 12:1317-1324. [PubMed: 16489089]

[65]. Desai, N. Drug Delivery Report. 16th edition. 2007/2008. Nab technology: a drug delivery platform utilising endothelial gp60 receptor-based transport and tumour-derived SPARC for targeting; p. 37-41. 
[66]. Chrousos GP. Stress and disorders of the stress system. Nat. Rev. Endocrinol. 2009; 5:374-381. [PubMed: 19488073]

[67]. Fujita Y, Kakino A, Harada-Shiba M, Sato Y, Otsui K, Yoshimoto R, Sawamura T. C-reactive protein uptake by macrophage cell line via class-A scavenger receptor. Clin. Chem. 2010; 56:478-481. [PubMed: 20075180]

[68]. Mihlan M, Stippa S, Józsi M. Monomeric CRP contributes to complement control in fluid phase and on cellular surfaces and increases phagocytosis by recruiting factor H. Cell Death and Differ. 2009; 16:1630-1640.

[69]. Farokhzad OC, Langer R. Impact of nanotechnology on drug delivery. ACS Nano. 2009; 3:1620. [PubMed: 19206243]

[70]. Mammen M, Choi SK, Whitesides GM. Polyvalent interactions in biological systems: implications for design and use of multivalent ligands and inhibitors. Angew. Chem. Int. Edit. 1998; 37:2754-2794.

[71]. Rao J, Lahiri J, Isaacs L, Weis RM, Whitesides GM. A trivalent system from Vancomycin-DAla-D-Ala with higher affinity than avidin-biotin. Science. 1998; 280:708-711. [PubMed: 9563940]

[72]. Gao H, Shi W, Freund LB. Mechanics of receptor-mediated endocytosis. Proc. Natl. Acad. Sci. USA. 2005; 102:9469-9474. [PubMed: 15972807]

[73]. Peer D, Karp JM, Hong S, Farokhzad OC, Margalit R, Langer R. Nanocarriers as an emerging platform for cancer therapy. Nat. Nanotechnol. 2007; 2:751-760. [PubMed: 18654426]

[74]. Shi J, Xiao Z, Kamaly N, Farokhzad OC. Self-assembled targeted nanoparticles: evolution of technologies and bench to bedside translation. Acc. Chem. Res. 2011; 44:1123-1134. [PubMed: 21692448]

[75]. Matthay KK, Abai AM, Cobb S, Hong K, Papahadjopoulos D, Straubinger RM. Role of Ligand in Antibody-directed Endocytosis of Liposomes by Human T-Leukemia Cells. Cancer Res. 1989; 49:4879-4886. [PubMed: 2788031]

[76]. Qian ZM, Li H, Sun H, Ho K. Targeted drug delivery via the transferrin receptor-mediated endocytosis pathway. Pharmacol. Rev. 2002; 54:561-587. [PubMed: 12429868]

[77]. Friden PM, Walus LR, Musso GF, Taylor MA, Malfroy B, Starzyk RM. Anti-transferrin receptor antibody and antibody-drug conjugates cross the blood-brain barrier. Proc. Natl. Acad. Sci. U. S. A. 1991; 88:4771-4775. [PubMed: 2052557]

[78]. Dautry-Varsat A, Ciechanover A, Lodish HF. pH and the recycling of transferrin during receptormediated endocytosis. Proc. Natl. Acad. Sci. U. S. A. 1983; 80:2258-2262. [PubMed: 6300903]

[79]. Davis ME. The first targeted delivery of siRNA in humans via a self-assembling, cyclodextrin polymer-based nanoparticle: from concept to clinic. Mol. Pharm. 2009; 6:659-668. [PubMed: 19267452]

[80]. Davis ME, Zuckerman JE, Choi CH, Seligson D, Tolcher A, Alabi CA, Yen Y, Heidel JD, Ribas A. Evidence of RNAi in humans from systemically administered siRNA via targeted nanoparticles. Nature. 2010; 464:1067-1070. [PubMed: 20305636]

[81]. Tsutsui S, Ohno S, Murakami S, Hachitanda Y, Oda S. Prognostic value of epidermal growth factor receptor (EGFR) and its relationship to the estrogen receptor status in 1029 patients with breast cancer. Breast Cancer Res. Tr. 2002; 71:67-75.

[82]. Milane L, Duan Z, Amiji M. Therapeutic efficacy and safety of paclitaxel/lonidamine loaded EGFR-targeted nanoparticles for the treatment of multi-drug resistant cancer. PLoS One. 2011; 6:e24075. [PubMed: 21931642]

[83]. Zhang XQ, Lam R, Xu X, Chow EK, Kim HJ, Ho D. Multimodal nanodiamond drug delivery carriers for selective targeting, imaging, and enhanced chemotherapeutic efficacy. Adv. Mater. 2011; 23:4770-4775. [PubMed: 21932280]

[84]. Irvin WJ Jr. Carey LA. What is triple-negative breast cancer? Eur. J. Cancer. 2008; 44:27992805. [PubMed: 19008097]

[85]. Lidke DS, Nagy P, Heintzmann R, Arndt-Jovin DJ, Post JN, Grecco HE, Jares-Erijman EA, Jovin TM. Quantum dot ligands provide new insights into erbB/HER receptor-mediated signal transduction. Nat. Biotechnol. 2004; 22:198-203. [PubMed: 14704683] 
[86]. Leamon CP, Low PS. Delivery of macromolecules into living cells: a method that exploits folate receptor endocytosis. Proc. Natl. Acad. Sci. U. S. A. 1991; 88:5572-5576. [PubMed: 2062838]

[87]. Sega EI, Low PS. Tumor detection using folate receptor-targeted imaging agents. Cancer Metast. Rev. 2008; 27:655-664.

[88]. Kawaguchi R, Yu J, Honda J, Hu J, Whitelegge J, Ping P, Wiita P, Bok D, Sun H. A Membrane Receptor for Retinol Binding Protein Mediates Cellular Uptake of Vitamin A. Science. 2007; 315:820-825. [PubMed: 17255476]

[89]. Sato Y, Murase K, Kato J, Kobune M, Sato T, Kawano Y, Takimoto R, Takada K, Miyanishi K, Matsunaga T, Takayam T, Niitsu Y. Resolution of liver cirrhosis using vitamin A-coupled liposomes to deliver siRNA against a collagen-specific chaperone. Nat. Biotechnol. 2008; 26:431-442. [PubMed: 18376398]

[90]. Farokhzad OC, Cheng J, Teply BA, Sherifi I, Jon S, Kantoff PW, Richie JP, Langer R. Targeted nanoparticle-aptamer bioconjugates for cancer chemotherapy in vivo. Proc. Natl. Acad. Sci. U. S. A. 2006; 103:6315-6320. [PubMed: 16606824]

[91]. Dhar S, Kolishetti N, Lippard SJ, Farokhzad OC. Targeted delivery of cisplatin prodrug for safer and more effective prostate cancer therapy in vivo. Proc. Natl. Acad. Sci. U. S. A. 2011; 108:1850-1855. [PubMed: 21233423]

[92]. Griffin JD, Linch D, Sabbath K, Larcom P, Schlossman SF. A monoclonal antibody reactive with normal and leukemic human myeloid progenitor cells. Leukemia Res. 1984; 8:521-534. [PubMed: 6590930]

[93]. Simard P, Leroux JC. pH-sensitive immunoliposomes specific to the CD33 cell surface antigen of leukemic cells. Int. J. Pharm. 2009; 381:86-96. [PubMed: 19446624]

[94]. Torchilin VP, Lukyanov AN, Gao Z, Papahadjopoulos-Sternberg B. Immunomicelles: targeted pharmaceutical carriers for poorly soluble drugs. Proc. Natl. Acad. Sci. U. S. A. 2003; 100:60396044. [PubMed: 12716967]

[95]. Koning GA, Morselt HWM, Gorter A, Allen TM, Zalipsky S, Kamps JAAM, Scherphof GL. Pharmacokinetics of Differently Designed Immunoliposome Formulations in Rats with or without Hepatic Colon Cancer Metastases. Pharm. Res. 2001; 18:1291-1298. [PubMed: 11683242]

[96]. Allen TM. Ligand-targeted therapeutics in anticancer therapy. Nat. Rev. Cancer. 2002; 2:750763. [PubMed: 12360278]

[97]. Park JW, Hong K, Kirpotin DB, Colbern G, Shalaby R, Baselga J, Shao Y, Nielsen UB, Marks JD, Moore D, Papahadjopoulos D, Benz C. Anti-HER2 immunoliposomes: enhanced efficacy attributable to targeted delivery. Clin. Cancer Res. 2002; 8:1172-1181. [PubMed: 11948130]

[98]. McDevitt MR, Chattopadhyay D, Kappel BJ, Jaggi JS, Schiffman SR, Antczak C, Njardarson JT, Brentjens R, Scheinberg DA. Tumor Targeting with Antibody-Functionalized, Radiolabeled Carbon Nanotubes. J. Nucl. Med. 2007; 48:1180-1189. [PubMed: 17607040]

[99]. Simard P, Leroux JC. In vivo evaluation of $\mathrm{pH}$-sensitive polymer-based immunoliposomes targeting the CD33 antigen. Mol. Pharm. 2010; 7:1098-1107. [PubMed: 20476756]

[100]. Veiseh O, Gunn JW, Kievit FM, Sun C, Fang C, Lee JSH, Zhang M. Inhibition of Tumor-Cell Invasion with Chlorotoxin-Bound Superparamagnetic Nanoparticles. Small. 2009; 5:256-264. [PubMed: 19089837]

[101]. Weissleder R, Kelly K, Yi Sun E, Shtatland T, Josephson L. Cell-specific targeting of nanoparticles by multivalent attachment of small molecules. Nat. Biotechnol. 2005; 23:14181423. [PubMed: 16244656]

[102]. Haun JB, Devaraj NK, Hilderbrand SA, Lee H, Weissleder R. Bioorthogonal chemistry amplifies nanoparticle binding and enhances the sensitivity of cell detection. Nat. Nanotechnol. 2010; 5:660-665. [PubMed: 20676091]

[103]. Müller MK, Brunsweld L. A supramolecular polymer as a self-assembling polyvalent scaffold. Angew. Chem. Int. Edit. 2009; 48:2921-2924.

[104]. Chung HJ, Reiner T, Budin G, Min C, Liong M, Issadore D, Lee H, Weissleder R. Ubiquitous Detection of Gram-Positive Bacteria with Bioorthogonal Magnetofluorescent Nanoparticles. ACS Nano. 2011; 5:8834-8841. [PubMed: 21967150] 
[105]. Kamaly N, Xiao Z, Valencia PM, Radovic-Moreno AF, Farokhzad OC. Targeted polymeric therapeutic nanoparticles: design, development and clinical translation. Chem. Soc. Rev. 2012; 41:2971-3010. [PubMed: 22388185]

[106]. Burg M, Ravey EP, Gonzales M, Amburn E, Faix PH, Baird A, Larocca D. Selection of internalizing ligand-display phage using rolling circle amplification for phage recovery. DNA Cell Biol. 2004; 23:457-462. [PubMed: 15294095]

[107]. Hild W, Pollinger K, Caporale A, Cabrele C, Keller M, Pluym N, Buschauer A, Rachel R, Tessmar J, Breunig M, Goepferich A. G protein-coupled receptors function as logic gates for nanoparticle binding and cell uptake. Proc. Natl. Acad. Sci. U. S. A. 2010; 107:10667-10672. [PubMed: 20498042]

[108]. Xiao Z, Levy-Nissenbaum E, Alexis F, Luptak A, Teply BA, Chan JM, Shi J, Digga E, Cheng J, Langer R, Farokhzad OC. Engineering of targeted nanoparticles for cancer therapy using internalizing aptamers isolated by cell-uptake selection. ACS Nano. 2012; 6:696-704. [PubMed: 22214176]

[109]. Yang L, Zhang X, Ye M, Jiang J, Yang R, Fu T, Chen Y, Wang K, Liu C, Tan W. Aptamerconjugated nanomaterials and their applications. Adv Drug Deliv Rev. 2011; 63:1361-1370. [PubMed: 22016112]

[110]. Jiang W, Kim BY, Rutka JT, Chan WC. Nanoparticle-mediated cellular response is sizedependent. Nat. Nanotechnol. 2008; 3:145-150. [PubMed: 18654486]

[111]. Gu F, Zhang L, Teply BA, Mann N, Wang A, Radovic-Moreno AF, Langer R, Farokhzad OC. Precise engineering of targeted nanoparticles by using self-assembled biointegrated block copolymers. Proc. Natl. Acad. Sci. U. S. A. 2008; 105:2586-2591. [PubMed: 18272481]

[112]. Wang J, Tian S, Petros RA, Napier ME, DeSimone J. The complex role of multivalency in nanoparticles targeting the transferrin receptor for cancer therapies. J. Am. Chem. Soc. 2010; 132:11306-11313. [PubMed: 20698697]

[113]. Vasey PA, Kaye SB, Morrison R, Twelves C, Wilson P, Duncan R, Thomson AH, Murray LS, Hilditch TE, Murray T, Burtles S, Fraier D, Frigerio E, Cassidy J. Phase I clinical and pharmacokinetic study of PK1 [N-(2-hydroxypropyl)methacrylamide copolymer doxorubicin]: first member of a new class of chemotherapeutic agents-drug-polymer conjugates. Cancer Research Campaign Phase I/II Committee. Clin. Cancer Res. 1999; 5:83-94. [PubMed: 9918206]

[114]. Miller K, Erez R, Segal E, Shabat D, Satchi-Fainaro R. Targeting bone metastases with a bispecific anticancer and antiangiogenic polymer-alendronate-taxane conjugate. Angew. Chem. Int. Edit. 2009; 48:2949-2954.

[115]. Ulbrich K, Subr V. Polymeric anticancer drugs with pH-controlled activation. Adv. Drug Deliv. Rev. 2004; 56:1023-1050. [PubMed: 15066758]

[116]. Bareford LM, Swaan PW. Endocytic mechanisms for targeted drug delivery. Adv. Drug Deliv. Rev. 2007; 59:748-758. [PubMed: 17659804]

[117]. Whitehead KA, Langer R, Anderson DG. Knocking down barriers: advances in siRNA delivery. Nat. Rev. Drug Discov. 2009; 8:129-138. [PubMed: 19180106]

[118]. Duncan R. Polymer conjugates as anticancer nanomedicines. Nat. Rev. Cancer. 2006; 6:688701. [PubMed: 16900224]

[119]. Minko T, Kopeckova P, Pozharov V, Kopecek J. HPMA copolymer bound adriamycin overcomes MDR1 gene encoded resistance in a human ovarian carcinoma cell line. J. Control Release. 1998; 54:223-233. [PubMed: 9724909]

[120]. Singer JW, Shaffer S, Baker B, Bernareggi A, Stromatt S, Nienstedt D, Besman M. Paclitaxel poliglumex (XYOTAX; CT-2103): an intracellularly targeted taxane. Anticancer Drugs. 2005; 16:243-254. [PubMed: 15711176]

[121]. Seymour LW, Ulbrich K, Steyger PS, Brereton M, Subr V, Strohalm J, Duncan R. Tumour tropism and anti-cancer efficacy of polymer-based doxorubicin prodrugs in the treatment of subcutaneous murine B16F10 melanoma. Br. J. Cancer. 1994; 70:636-641. [PubMed: 7917909]

[122]. Gianasi E, Buckley RG, Latigo J, Wasil M, Duncan R. HPMA copolymers platinates containing dicarboxylato ligands. Preparation, characterisation and in vitro and in vivo evaluation. J. Drug Target. 2002; 10:549-556. [PubMed: 12683722] 
[123]. Duncan R, Vicent MJ. Do HPMA copolymer conjugates have a future as clinically useful nanomedicines? A critical overview of current status and future opportunities. Adv. Drug Deliver. Rev. 2010; 62:272-282.

[124]. Meerum Terwogt JM, ten Bokkel Huinink WW, Schellens JH, Schot M, Mandjes IA, Zurlo MG, Rocchetti M, Rosing H, Koopman FJ, Beijnen JH. Phase I clinical and pharmacokinetic study of PNU166945, a novel water-soluble polymer-conjugated prodrug of paclitaxel. Colloq. Inse. $2001 ; 12: 315-323$.

[125]. Schoemaker NE, Van Kesteren C, Rosing H, Jansen S, Swart M, Lieverst J, Fraier D, Breda M, Pellizzoni C, Spinelli R, Grazia Porro M, Beijnen JH, Schellens JH, ten Bokkel Huinink WW. A phase I and pharmacokinetic study of MAG-CPT, a water-soluble polymer conjugate of camptothecin. Br. J. Cancer. 2002; 87:608-614. [PubMed: 12237769]

[126]. Bissett D, Cassidy J, de Bono JS, Muirhead F, Main M, Robson L, Fraier D, Magne ML, Pellizzoni C, Porro MG, Spinelli R, Speed W, Twelves C. Phase I and pharmacokinetic (PK) study of MAG-CPT (PNU 166148): a polymeric derivative of camptothecin (CPT). Br. J. Cancer. 2004; 91:50-55. [PubMed: 15187995]

[127]. Wachters FM, Groen HJ, Maring JG, Gietema JA, Porro M, Dumez H, de Vries EG, van Oosterom AT. A phase I study with MAG-camptothecin intravenously administered weekly for 3 weeks in a 4-week cycle in adult patients with solid tumours. Br. J. Cancer. 2004; 90:2261-2267. [PubMed: 15150611]

[128]. Duncan R, Cable HC, Lloyd JB, Rejmanova P, Kopecek J. Degradation of side-chains of N-(2hydroxypropyl)methacrylamide copolymers by lysosomal thiol-proteinases. Biosci. Rep. 1982; 2:1041-1046. [PubMed: 6762230]

[129]. Castino R, Demoz M, Isidoro C. Destination 'lysosome': a target organelle for tumour cell killing? J. Mol. Recognit. 2003; 16:337-348. [PubMed: 14523947]

[130]. Singer JW, Baker B, De Vries P, Kumar A, Shaffer S, Vawter E, Bolton M, Garzone P. Poly(L)-glutamic acid-paclitaxel (CT-2103) [XYOTAX], a biodegradable polymeric drug conjugate: characterization, preclinical pharmacology, and preliminary clinical data. Adv. Exp. Med. Biol. 2003; 519:81-99. [PubMed: 12675210]

[131]. Shaffer SA, Baker Lee C, Kumar A, Singer JW. Proteolysis of xyotax by lysosomal cathepsin B; metabolic profiling in tumor cells using LC-MS. Eur. J. Cancer. 2002; 38:S129-S129.

[132]. Langer CJ. CT-2103: a novel macromolecular taxane with potential advantages compared with conventional taxanes. Clinical lung cancer. 2004; 6(Suppl 2):S85-88. [PubMed: 15638965]

[133]. Langer CJ, Socinski MA, Ross H, O’Byrne KJ. Paclitaxel poliglumex (PPX)/carboplatin vs paclitaxel/carboplatin for the treatment of PS2 patients with chemotherapy-naive advanced nonsmall cell lung cancer (NSCLC): A phase III study. J. Clin. Oncol. 2005; 23:1095S-1095S.

[134]. Paz-Ares L, Ross H, O’Brien M, Riviere A, Gatzemeier U, Von Pawel J, Kaukel E, Freitag L, Digel W, Bischoff H, Garcia-Campelo R, Iannotti N, Reiterer P, Bover I, Prendiville J, Eisenfeld A, Oldham F, Bandstra B, Singer J, Bonomi P. Phase III trial comparing paclitaxel poliglumex vs docetaxel in the second-line treatment of non-small-cell lung cancer. Br. J. Cancer. 2008; 98:1608-1613. [PubMed: 18475293]

[135]. Kremer M, Judd J, Rifkin B, Auszmann J, Oursler MJ. Estrogen modulation of osteoclast lysosomal enzyme secretion. J. Cell. Biochem. 1995; 57:271-279. [PubMed: 7759564]

[136]. Mukherjee S, Ghosh RN, Maxfield FR. Endocytosis. Physiol Rev. 1997; 77:759-803. [PubMed: 9234965]

[137]. Roux E, Lafleur M, Lataste É, Moreau P, Leroux J-C. On the characterization of pH-sensitive Liposome/Polymer Complexes. Biomacromolecules. 2003; 4:240-248. [PubMed: 12625718]

[138]. Bertrand N, Fleischer JG, Wasan KM, Leroux JC. Pharmacokinetics and biodistribution of $N$ isopropylacrylamide copolymers for the design of $\mathrm{pH}$-sensitive liposomes. Biomaterials. 2009; 30:2598-2605. [PubMed: 19176241]

[139]. Johnson RP, Jeong YI, Choi E, Chung CW, Kang DH, Oh SO, Suh H, Kim I. Biocompatible Poly(2-hydroxyethyl methacrylate)-b-poly(L-histidine) Hybrid Materials for $\mathrm{pH}$-Sensitive Intracellular Anticancer Drug Delivery. Adv. Funct. Mater. 2012; 22:1058-1068. 
[140]. Xu Q, Liu YX, Su SS, Li W, Chen CY, Wu Y. Anti-tumor activity of paclitaxel through dualtargeting carrier of cyclic RGD and transferrin conjugated hyperbranched copolymer nanoparticles. Biomaterials. 2012; 33:1627-1639. [PubMed: 22118775]

[141]. Gao W, Langer R, Farokhzad OC. Poly(ethylene glycol) with observable shedding. Angew. Chem. Int. Edit. 2010; 49:6567-6571.

[142]. Cerritelli S, Velluto D, Hubbell JA. PEG-SS-PPS: reduction-sensitive disulfide block copolymer vesicles for intracellular drug delivery. Biomacromolecules. 2007; 8:1966-1972. [PubMed: 17497921]

[143]. Plank C, Oberhauser B, Mechtler K, Koch C, Wagner E. The influence of endosome-disruptive peptides on gene transfer using synthetic virus-like gene transfer systems. J. Biol. Chem. 1994; 269:12918-12924. [PubMed: 8175709]

[144]. Varkouhi AK, Scholte M, Storm G, Haisma HJ. Endosomal escape pathways for delivery of biologicals. J. Control. Release. 2011; 151:220-228. [PubMed: 21078351]

[145]. Palanca-Wessels MC, Convertine AJ, Cutler-Storm R, Booth GC, Lee F, Berguig GY, Stayton PS, Press O. Anti-CD22 antibody targeting of pH-responsive micelles enhances small interfering RNA delivery and gene silencing in lymphoma cells. Mol. Ther. 2011; 19:1529-1537. [PubMed: 21629223]

[146]. Yessine M-A, Lafleur M, Meier C, Petereit H-U, Leroux J-C. Characterization of the membrane-destabilizing properties of different $\mathrm{pH}$-sensitive methacrylic acid copolymers. Biochim. Biophys. Acta. 2003; 1613:28-38. [PubMed: 12832084]

[147]. Muro S, Schuchman EH, Muzykantov VR. Lysosomal enzyme delivery by ICAM-1-targeted nanocarriers bypassing glycosylation- and clathrin-dependent endocytosis. Mol. Ther. 2006; 13:135-141. [PubMed: 16153895]

[148]. Wu H, Hait WN, Yang JM. Small interfering RNA-induced suppression of MDR1 (Pglycoprotein) restores sensitivity to multidrug-resistant cancer cells. Cancer Res. 2003; 63:15151519. [PubMed: 12670898]

[149]. Pai SI, Lin YY, Macaes B. A. Meneshian, C.F. Hung, T.C. Wu, Prospects of RNA interference therapy for cancer. Gene Ther. 2006; 13:464-477. [PubMed: 16341059]

[150]. Marshall J. Draft guidelines for nanomedicine unveiled. Nature News. 2011 doi:10.1038/news. 2011.562.

[151]. Golub TR, Slonim DK, Tamayo P, Huard C, Gaasenbeek M, Mesirov JP, Coller H, Loh ML, Downing JR, Caligiuri MA, Bloomfield CD, Lander ES. Molecular classification of cancer: class discovery and class prediction by gene expression monitoring. Science. 1999; 286:531-537. [PubMed: 10521349]

[152]. Alizadeh AA, Eisen MB, Davis RE, Ma C, Lossos IS, Rosenwald A, Boldrick JC, Sabet H, Tran T, Yu X, Powell JI, Yang L, Marti GE, Moore T, Hudson J Jr. Lu L, Lewis DB, Tibshirani R, Sherlock G, Chan WC, Greiner TC, Weisenburger DD, Armitage JO, Warnke R, Levy R, Wilson W, Grever MR, Byrd JC, Botstein D, Brown PO, Staudt LM. Distinct types of diffuse large Bcell lymphoma identified by gene expression profiling. Nature. 2000; 403:503-511. [PubMed: 10676951]

[153]. Perou CM, Sorlie T, Eisen MB, van de Rijn M, Jeffrey SS, Rees CA, Pollack JR, Ross DT, Johnsen H, Akslen LA, Fluge O, Pergamenschikov A, Williams C, Zhu SX, Lonning PE, Borresen-Dale AL, Brown PO, Botstein D. Molecular portraits of human breast tumours. Nature. 2000; 406:747-752. [PubMed: 10963602]

[154]. Bittner M, Meltzer P, Chen Y, Jiang Y, Seftor E, Hendrix M, Radmacher M, Simon R, Yakhini Z, Ben-Dor A, Sampas N, Dougherty E, Wang E, Marincola F, Gooden C, Lueders J, Glatfelter A, Pollock P, Carpten J, Gillanders E, Leja D, Dietrich K, Beaudry C, Berens M, Alberts D, Sondak V. Molecular classification of cutaneous malignant melanoma by gene expression profiling. Nature. 2000; 406:536-540. [PubMed: 10952317]

[155]. Azzazy HM, Mansour MM, Kazmierczak SC. Nanodiagnostics: a new frontier for clinical laboratory medicine. Clin. Chem. 2006; 52:1238-1246. [PubMed: 16709623]

[156]. Geho DH, Jones CD, Petricoin EF, Liotta LA. Nanoparticles: potential biomarker harvesters. Curr. Opin. Chem. Biol. 2006; 10:56-61. [PubMed: 16413816] 
[157]. Peng XH, Cao ZH, Xia JT, Carlson GW, Lewis MM, Wood WC, Yang L. Real-time detection of gene expression in cancer cells using molecular beacon imaging: new strategies for cancer research. Cancer Res. 2005; 65:1909-1917. [PubMed: 15753390]

[158]. Yezhelyev MV, Al-Hajj A, Morris C, Marcus AI, Liu T, Lewis M, Cohen C, Zrazhevskiy P, Simons JW, Rogatko A, Nie S, Gao X, O'Regan RM. In situ molecular profiling of breast cancer biomarkers with multicolor quantum dots. Adv. Mater. 2007; 19:3146-3151.

[159]. Luchini A, Geho DH, Bishop B, Tran D, Xia C, Dufour RL, Jones CD, Espina V, Patanarut A, Zhou W, Ross MM, Tessitore A, Petricoin EF 3rd, Liotta LA. Smart hydrogel particles: biomarker harvesting: one-step affinity purification, size exclusion, and protection against degradation. Nano Lett. 2008; 8:350-361. [PubMed: 18076201]

[160]. Weissleder R, Stark DD, Engelstad BL, Bacon BR, Compton CC, White DL, Jacobs P, Lewis J. Superparamagnetic iron oxide: pharmacokinetics and toxicity. AJR Am. J. Roentgenol. 1989; 152:167-173. [PubMed: 2783272]

[161]. Dave SR, Gao X. Monodisperse magnetic nanoparticles for biodetection, imaging, and drug delivery: a versatile and evolving technology. Wiley Interdiscip. Rev. Nanomed. Nanobiotechnol. 2009; 1:583-609. [PubMed: 20049819]

[162]. Emerich DF, Thanos CG. Targeted nanoparticle-based drug delivery and diagnosis. J. Drug Target. 2007; 15:163-183. [PubMed: 17454354]

[163]. Wang Y. Superparamagnetic iron oxide based MRI contrast agents: Current status of clinical application. Quantitative imaging in medicine and surgery. 2011; 1:35-40.

[164]. Kim YK, Lee JM, Kim CS, Chung GH, Kim CY, Kim IH. Detection of liver metastases: gadobenate dimeglumine-enhanced three-dimensional dynamic phases and one-hour delayed phase MR imaging versus superparamagnetic iron oxide-enhanced MR imaging. Eur. Radiol. 2005; 15:220-228. [PubMed: 15624108]

[165]. Schnorr J, Wagner S, Abramjuk C, Wojner I, Schink T, Kroencke TJ, Schellenberger E, Hamm B, Pilgrimm H, Taupitz M. Comparison of the iron oxide-based blood-pool contrast medium VSOP-C184 with gadopentetate dimeglumine for first-pass magnetic resonance angiography of the aorta and renal arteries in pigs. Invest Radiol. 2004; 39:546-553. [PubMed: 15308937]

[166]. Bremerich J, Bilecen D, Reimer P. MR angiography with blood pool contrast agents. Eur. Radiol. 2007; 17:3017-3024. [PubMed: 17639407]

[167]. Reimer P, Bremer C, Allkemper T, Engelhardt M, Mahler M, Ebert W, Tombach B. Myocardial perfusion and MR angiography of chest with SH U 555 C: results of placebo-controlled clinical phase I study. Radiology. 2004; 231:474-481. [PubMed: 15044749]

[168]. Allkemper T, Bremer C, Matuszewski L, Ebert W, Reimer P. Contrast-enhanced blood-pool MR angiography with optimized iron oxides: effect of size and dose on vascular contrast enhancement in rabbits. Radiology. 2002; 223:432-438. [PubMed: 11997549]

[169]. Arbab AS, Janic B, Haller J, Pawelczyk E, Liu W, Frank JA. In Vivo Cellular Imaging for Translational Medical Research. Curr. Med. Imaging Rev. 2009; 5:19-38. [PubMed: 19768136]

[170]. Derfus AM, Chan WCW, Bhatia SN. Intracellular delivery of quantum dots for live cell labeling and organelle tracking. Adv. Mater. 2004; 16:961-966.

[171]. Michalet X, Pinaud FF, Bentolila LA, Tsay JM, Doose S, Li JJ, Sundaresan G, Wu AM, Gambhir SS, Weiss S. Quantum dots for live cells, in vivo imaging, and diagnostics. Science. 2005; 307:538-544. [PubMed: 15681376]

[172]. Kramer-Marek G, Kiesewetter DO, Capala J. Changes in HER2 expression in breast cancer xenografts after therapy can be quantified using PET and (18)F-labeled affibody molecules. J. Nucl. Med. 2009; 50:1131-1139. [PubMed: 19525458]

[173]. Lee JH, Huh YM, Jun YW, Seo JW, Jang JT, Song HT, Kim S, Cho EJ, Yoon HG, Suh JS, Cheon J. Artificially engineered magnetic nanoparticles for ultra-sensitive molecular imaging. Nat. Med. 2007; 13:95-99. [PubMed: 17187073]

[174]. Weissleder R, Lee AS, Khaw BA, Shen T, Brady TJ. Antimyosin-labeled monocrystalline iron oxide allows detection of myocardial infarct: MR antibody imaging. Radiology. 1992; 182:381385. [PubMed: 1732953] 
[175]. Kircher MF, Mahmood U, King RS, Weissleder R, Josephson L. A multimodal nanoparticle for preoperative magnetic resonance imaging and intraoperative optical brain tumor delineation. Cancer Res. 2003; 63:8122-8125. [PubMed: 14678964]

[176]. Chen J, Tung CH, Mahmood U, Ntziachristos V, Gyurko R, Fishman MC, Huang PL, Weissleder R. In vivo imaging of proteolytic activity in atherosclerosis. Circulation. 2002; 105:2766-2771. [PubMed: 12057992]

[177]. Sosnovik DE, Nahrendorf M, Deliolanis N, Novikov M, Aikawa E, Josephson L, Rosenzweig A, Weissleder R, Ntziachristos V. Fluorescence tomography and magnetic resonance imaging of myocardial macrophage infiltration in infarcted myocardium in vivo. Circulation. 2007; 115:1384-1391. [PubMed: 17339546]

[178]. Weissleder R, Tung CH, Mahmood U, Bogdanov A Jr. In vivo imaging of tumors with protease-activated near-infrared fluorescent probes. Nat. Biotechnol. 1999; 17:375-378. [PubMed: 10207887]

[179]. Song Y, Xu X, MacRenaris KW, Zhang XQ, Mirkin CA, Meade TJ. Multimodal gadoliniumenriched DNA-gold nanoparticle conjugates for cellular imaging. Angew. Chem. Int. Edit. 2009; 48:9143-9147.

[180]. Koole R, van Schooneveld MM, Hilhorst J, Castermans K, Cormode DP, Strijkers GJ, de Mello Donega C, Vanmaekelbergh D, Griffioen AW, Nicolay K, Fayad ZA, Meijerink A, Mulder WJ. Paramagnetic lipid-coated silica nanoparticles with a fluorescent quantum dot core: a new contrast agent platform for multimodality imaging. Bioconjug. Chem. 2008; 19:2471-2479. [PubMed: 19035793]

[181]. Lee JH, Lee K, Moon SH, Lee Y, Park TG, Cheon J. All-in-one target-cell-specific magnetic nanoparticles for simultaneous molecular imaging and siRNA delivery. Angew. Chem. Int. Edit. 2009; 48:4174-4179.

[182]. Wang AZ, Bagalkot V, Vasilliou CC, Gu F, Alexis F, Zhang L, Shaikh M, Yuet K, Cima MJ, Langer R, Kantoff PW, Bander NH, Jon S, Farokhzad OC. Superparamagnetic iron oxide nanoparticle-aptamer bioconjugates for combined prostate cancer imaging and therapy. ChemMedChem. 2008; 3:1311-1315. [PubMed: 18613203]

[183]. Bagalkot V, Zhang L, Levy-Nissenbaum E, Jon S, Kantoff PW, Langer R, Farokhzad OC. Quantum dot-aptamer conjugates for synchronous cancer imaging, therapy, and sensing of drug delivery based on bi-fluorescence resonance energy transfer. Nano Lett. 2007; 7:3065-3070. [PubMed: 17854227]

[184]. Winter PM, Neubauer AM, Caruthers SD, Harris TD, Robertson JD, Williams TA, Schmieder AH, Hu G, Allen JS, Lacy EK, Zhang H, Wickline SA, Lanza GM. Endothelial alpha(v)beta3 integrin-targeted fumagillin nanoparticles inhibit angiogenesis in atherosclerosis. Arteriosclr. Thromb. Vasc. Biol. 2006; 26:2103-2109.

[185]. Flacke S, Fischer S, Scott MJ, Fuhrhop RJ, Allen JS, McLean M, Winter P, Sicard GA, Gaffney PJ, Wickline SA, Lanza GM. Novel MRI contrast agent for molecular imaging of fibrin: implications for detecting vulnerable plaques. Circulation. 2001; 104:1280-1285. [PubMed: 11551880]

[186]. Cyrus T, Abendschein DR, Caruthers SD, Harris TD, Glattauer V, Werkmeister JA, Ramshaw JA, Wickline SA, Lanza GM. MR three-dimensional molecular imaging of intramural biomarkers with targeted nanoparticles. J. Cardiovasc. Magn. R. 2006; 8:535-541.

[187]. Marchant GE. Small is Beautiful: What Can Nanotechnology Do for Personalized Medicine? Current Pharmacogenomics and Personalized Medicine. 2009; 7:231-237.

[188]. Karathanasis E, Suryanarayanan S, Balusu SR, McNeeley K, Sechopoulos I, Karellas A, Annapragada AV, Bellamkonda RV. Imaging nanoprobe for prediction of outcome of nanoparticle chemotherapy by using mammography. Radiology. 2009; 250:398-406. [PubMed: 19188313]

[189]. Chan JM, Zhang L, Tong R, Ghosh D, Gao W, Liao G, Yuet KP, Gray D, 2141 Rhee JW, Cheng J, Golomb G, Libby P, Langer R, Farokhzad OC. Spatiotemporal controlled delivery of nanoparticles to injured vasculature. Proc. Natl. Acad. Sci. U. S. A. 2010; 107:2213-2218. [PubMed: 20133865] 
[190]. Lee M, Choi JS, Choi MJ, Pak YK, Rhee BD, Ko KS. DNA delivery to the mitochondria sites using mitochondrial leader peptide conjugated polyethylenimine. J. Drug Target. 2007; 15:115122. [PubMed: 17365282]

[191]. Hu CJ, Aryal S, Zhang L. Nanoparticle-assisted combination therapies for effective cancer treatment. Therapeutic Delivery. 2010; 1:323-334. [PubMed: 22816135]

[192]. Kolishetti N, Dhar S, Valencia PM, Lin LQ, Karnik R, Lippard SJ, Langer R, Farokhzad OC. Engineering of self-assembled nanoparticle platform for precisely controlled combination drug therapy. Proc. Natl. Acad. Sci. U. S. A. 2010; 107:17939-17944. [PubMed: 20921363]

[193]. Sengupta S, Eavarone D, Capila I, Zhao G, Watson N, Kiziltepe T, Sasisekharan R. Temporal targeting of tumour cells and neovasculature with a nanoscale delivery system. Nature. 2005; 436:568-572. [PubMed: 16049491]

[194]. Patil YB, Swaminathan SK, Sadhukha T, Ma L, Panyam J. The use of nanoparticle-mediated targeted gene silencing and drug delivery to overcome tumor drug resistance. Biomaterials. 2010; 31:358-365. [PubMed: 19800114]

[195]. De Jong WH, Borm PJ. Drug delivery and nanoparticles:applications and hazards. Int. J. Nanomedicine. 2008; 3:133-149. [PubMed: 18686775]

[196]. Kagan VE, Bayir H, Shvedova AA. Nanomedicine and nanotoxicology: two sides of the same coin. Nanomedicine. 2005; 1:313-316. [PubMed: 17292104]

[197]. Shvedova AA, Kagan VE, Fadeel B. Close encounters of the small kind: adverse effects of manmade materials interfacing with the nano-cosmos of biological systems. Annu. Rev. Pharmacol. Toxicol. 2010; 50:63-88. [PubMed: 20055698]

[198]. Singh N, Manshian B, Jenkins GJ, Griffiths SM, Williams PM, Maffeis TG, Wright CJ, Doak SH. NanoGenotoxicology: the DNA damaging potential of engineered nanomaterials. Biomaterials. 2009; 30:3891-3914. [PubMed: 19427031]

[199]. Bhabra G, Sood A, Fisher B, Cartwright L, Saunders M, Evans WH, Surprenant A, LopezCastejon G, Mann S, Davis SA, Hails LA, Ingham E, Verkade P, Lane J, Heesom K, Newson R, Case CP. Nanoparticles can cause DNA damage across a cellular barrier. Nat. Nanotechnol. 2009; 4:876-883. [PubMed: 19893513]

[200]. Xia T, Li N, Nel AE. Potential health impact of nanoparticles. Annu. Rev. Publ. Health. 2009; 30:137-150.

[201]. Pan Y, Neuss S, Leifert A, Fischler M, Wen F, Simon U, Schmid G, Brandau W, JahnenDechent W. Size-dependent cytotoxicity of gold nanoparticles. Small. 2007; 3:1941-1949. [PubMed: 17963284]

[202]. Tsoli M, Kuhn H, Brandau W, Esche H, Schmid G. Cellular uptake and toxicity of Au55 clusters. Small. 2005; 1:841-844. [PubMed: 17193536]

[203]. De Jong WH, Hagens WI, Krystek P, Burger MC, Sips AJ, Geertsma RE. Particle sizedependent organ distribution of gold nanoparticles after intravenous administration. Biomaterials. 2008; 29:1912-1919. [PubMed: 18242692]

[204]. Nabiev I, Mitchell S, Davies A, Williams Y, Kelleher D, Moore R, Gun'ko YK, Byrne S, Rakovich YP, Donegan JF, Sukhanova A, Conroy J, Cottell D, Gaponik N, Rogach A, Volkov Y. Nonfunctionalized nanocrystals can exploit a cell's active transport machinery delivering them to specific nuclear and cytoplasmic compartments. Nano Lett. 2007; 7:3452-3461. [PubMed: 17949046]

[205]. Hardman R. A toxicologic review of quantum dots: toxicity depends on physicochemical and environmental factors. Environ. Health Persp. 2006; 114:165-172.

[206]. Sandhiya S, Dkhar SA, Surendiran A. Emerging trends of nanomedicine - an overview. Fundam. Clin. Pharm. 2009; 23:263-269.

[207]. Poland CA, Duffin R, Kinloch I, Maynard A, Wallace WA, Seaton A, Stone V, Brown S, Macnee W, Donaldson K. Carbon nanotubes introduced into the abdominal cavity of mice show asbestos-like pathogenicity in a pilot study. Nat. Nanotechnol. 2008; 3:423-428. [PubMed: 18654567]

[208]. Dostert C, Petrilli V, Van Bruggen R, Steele C, Mossman BT, Tschopp J. Innate immune activation through Nalp3 inflammasome sensing of asbestos and silica. Science. 2008; 320:674677. [PubMed: 18403674] 
[209]. Takagi A, Hirose A, Nishimura T, Fukumori N, Ogata A, Ohashi N, Kitajima S, Kanno J. Induction of mesothelioma in p53+/- mouse by intraperitoneal application of multi-wall carbon nanotube. J. Toxicol. Sci. 2008; 33:105-116. [PubMed: 18303189]

[210]. Shvedova AA, Kisin E, Murray AR, Johnson VJ, Gorelik O, Arepalli S, Hubbs AF, Mercer RR, Keohavong P, Sussman N, Jin J, Yin J, Stone S, Chen BT, Deye G, Maynard A, Castranova V, Baron PA, Kagan VE. Inhalation vs. aspiration of single-walled carbon nanotubes in C57BL/6 mice: inflammation, fibrosis, oxidative stress, and mutagenesis. Am. J. Physiol. Lung Cell Mol. Physiol. 2008; 295:L552-565. [PubMed: 18658273]

[211]. Sargent LM, Shvedova AA, Hubbs AF, Salisbury JL, Benkovic SA, Kashon ML, Lowry DT, Murray AR, Kisin ER, Friend S, McKinstry KT, Battelli L, Reynolds SH. Induction of aneuploidy by single-walled carbon nanotubes. Environ. Mol. Mutagen. 2009; 50:708-717. [PubMed: 19774611]

[212]. Sayes CM, Wahi R, Kurian PA, Liu Y, West JL, Ausman KD, Warheit DB, Colvin VL. Correlating nanoscale titania structure with toxicity: a cytotoxicity and inflammatory response study with human dermal fibroblasts and human lung epithelial cells. Toxicol. Sci. 2006; 92:174185. [PubMed: 16613837]

[213]. Oberdorster G, Oberdorster E, Oberdorster J. Nanotoxicology: an emerging discipline evolving from studies of ultrafine particles. Environ. Health Persp. 2005; 113:823-839.

[214]. Xiao GG, Wang M, Li N, Loo JA, Nel AE. Use of proteomics to demonstrate a hierarchical oxidative stress response to diesel exhaust particle chemicals in a macrophage cell line. J. Biol. Chem. 2003; 278:50781-50790. [PubMed: 14522998]

[215]. Nel AE, Diaz-Sanchez D, Li N. The role of particulate pollutants in pulmonary inflammation and asthma: evidence for the involvement of organic chemicals and oxidative stress. Curr. Opin. Pulm. Med. 2001; 7:20-26. [PubMed: 11140402]

[216]. Jones G, Brooks PM. Injectable gold compounds: an overview. Br. J. Rheumatol. 1996; 35:1154-1158. [PubMed: 8948305]

[217]. Fischer HC, Chan WC. Nanotoxicity: the growing need for in vivo study. Curr. Opin. Biotechnol. 2007; 18:565-571. [PubMed: 18160274]

[218]. Nemmar A, Hoylaerts MF, Hoet PH, Vermylen J, Nemery B. Size effect of intratracheally instilled particles on pulmonary inflammation and vascular thrombosis. Toxicol. Appl. Pharm. $2003 ; 186: 38-45$

[219]. Xia T, Kovochich M, Liong M, Zink JI, Nel AE. Cationic polystyrene nanosphere toxicity depends on cell-specific endocytic and mitochondrial injury pathways. ACS Nano. 2008; 2:8596. [PubMed: 19206551]

[220]. Brewer J, Gurel O. Nanomedicine: Issues of Privacy and Informed Consent. Nanotech. L. \& Bus. 2009; 6:45-57.

[221]. Gerlinger M, Rowan AJ, Horswell S, Larkin J, Endesfelder D, Gronroos E, Martinez P, Matthews N, Stewart A, Tarpey P, Varela I, Phillimore B, Begum S, McDonald NQ, Butler A, Jones D, Raine K, Latimer C, Santos CR, Nohadani M, Eklund AC, Spencer-Dene B, Clark G, Pickering L, Stamp G, Gore M, Szallasi Z, Downward J, Futreal PA, Swanton C. Intratumor heterogeneity and branched evolution revealed by multiregion sequencing. N. Engl. J. Med. 2012; 366:883-892. [PubMed: 22397650]

[222]. Longo DL. Tumor heterogeneity and personalized medicine. N. Engl. J. Med. 2012; 366:956957. [PubMed: 22397658]

[223]. Bertrand N, Bouvet C, Moreau P, Leroux JC. Transmembrane pH-gradient liposomes to treat cardiovascular drug intoxication. ACS Nano. 2010; 4:7552-7558. [PubMed: 21067150]

[224]. Forster V, Luciani P, Leroux JC. Treatment of calcium channel blocker-induced cardiovascular toxicity with drug scavenging liposomes. Biomaterials. 2012; 33:3578-3585. [PubMed: 22330848]

[225]. Abi-Mosleh L, Infante RE, Radhakrishnan A, Goldstein JL, Brown MS. Cyclodextrin overcomes deficient lysosome-to-endoplasmic reticulum transport of cholesterol in NiemannPick type C cells. Proc. Natl. Acad. Sci. U. S. A. 2009; 106:19316-19321. [PubMed: 19884502] 
[226]. Liu B, Turley SD, Burns DK, Miller AM, Repa JJ, Dietschy JM. Reversal of defective lysosomal transport in NPC disease ameliorates liver dysfunction and neurodegeneration in the npc1-/- mouse. Proc. Natl. Acad. Sci. U. S. A. 2009; 106:2377-2382. [PubMed: 19171898]

[227]. Wright JF, Wellman J, High KA. Manufacturing and regulatory strategies for clinical AAV2hRPE65. Curr. Gene Ther. 2010; 10:341-349. [PubMed: 20712582]

[228]. Maguire AM, Simonelli F, Pierce EA, Pugh EN, Mingozzi F, Bennicelli J, Banfi S, Marshall KA, Testa F, Surace EM, Rossi S, Lyubarsky A, Arruda VR, Konkle B, Stone E, Sun J, Jacobs J, Dell'Osso L, Hertle R, Ma J-X, Redmond M, Zhu X, Hauck B, Zelenaia O, Shindler JS, Maguire MG, Wright JF, Volpe NJ, Wellman Mc Donnell J, Auricchio A, High KA, Bennett J. Safety and efficacy of gene transfer for Leber's congenital amaurosis. N. Engl. J. Med. 2008; 358:22402248. [PubMed: 18441370]

[229]. Maguire AM, High KA, Auricchio A, Wright JF, Pierce EA, Testa F, Mingozzi F, Bennicelli JL, Ying G.-s. Rossi S, Fulton A, Marshall KA, Banfi S, Chung DC, Morgan JIW, Hauck B, Zelenaia O, Zhu X, Raffini L, Coppieters F, De Baere E, Shindler KS, Volpe NJ, Surace EM, Acerra C, Lyubarsky A, Redmond TM, Stone E, Sun J, McDonnell JW, Leroy BP, Simonelli F, Bennett J. Age-dependent effects of RPE65 gene therapy for Leber's congenital amaurosis: a phase 1 dose-escalation trial. The Lancet. 2009; 374:1597-1605.

[230]. Manno CS, Arruda VR, Pierce GF, Glader B, Ragni M, Rasko J, Ozelo MC, Hoots K, Blatt P, Konkle B, Dake M, Kaye R, Razavi M, Zajko A, Zehnder J, Nakai H, Chew A, Leonard D, Wright JF, Lessard RR, Sommer JM, Tigges M, Sabatino D, Luk A, Jiang H, Mingozzi F, Couto L, Ertl HC, High KA, Kay MA. Successful transduction of liver in hemophilia by AAV-Factor IX and limitations imposed by the host immune response. Nat. Med. 2006; 12:342-347. [PubMed: 16474400]

[231]. Guarneri V, Barbieri E, Conte P. Biomarkers predicting clinical benefit: fact or fiction? J. Natl. Cancer Inst. 2011; 43:63-66. 


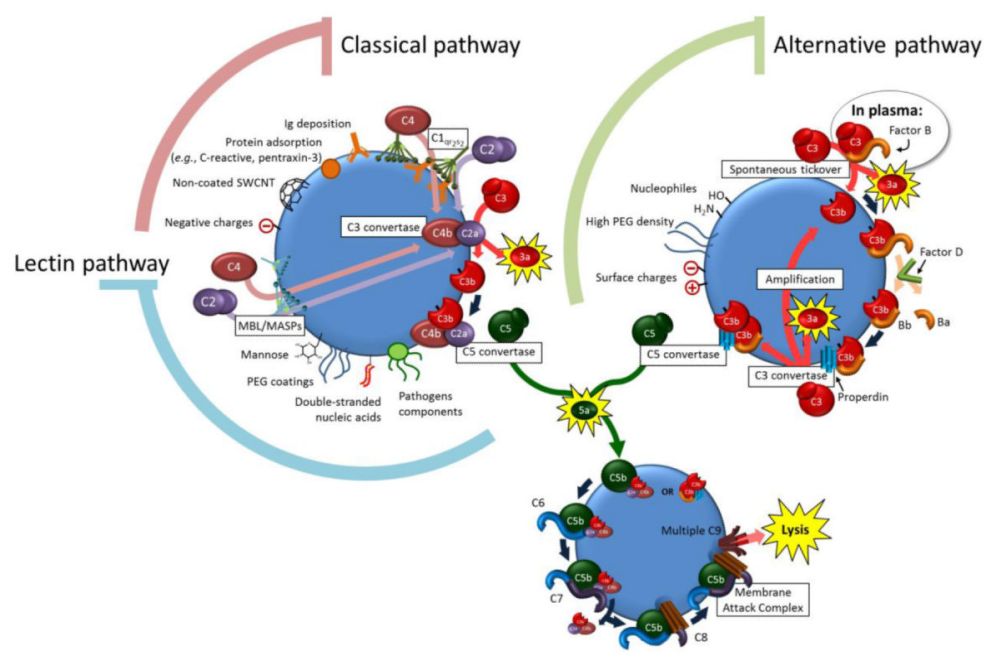

Figure 1.

The physicochemical properties of the nanomaterial surface can trigger the different pathways of complement cascade activation [49-55]. The classical pathway is activated through deposition of specific proteins like antibodies and others. The lectin pathway is triggered by the recognition of the surface by a Mannose-binding Lectin (MBL) through pathogen-associated motifs. The lectin subsequently interacts with a serine protease (MASP) to elicit the formation of a $\mathrm{C} 3$-convertase (C4b2a) analogously to the classical pathway. The spontaneous tickover responsible for the alternative pathway activation is constantly present in plasma. When not properly regulated, the preferred deposition of the $\mathrm{C} 3 \mathrm{~b}$ products on the surface of the nanomaterial amplifies the cascade activation. All 3 pathways lead to C5convertases that cleave $\mathrm{C} 5$ and lead to the deposition of the terminal membrane attack complex which can lyse pathogens and senescent cells, further releasing proinflammatory mediators. The release of proinflammatory chemoattractants is symbolized by the yellow outburst. 


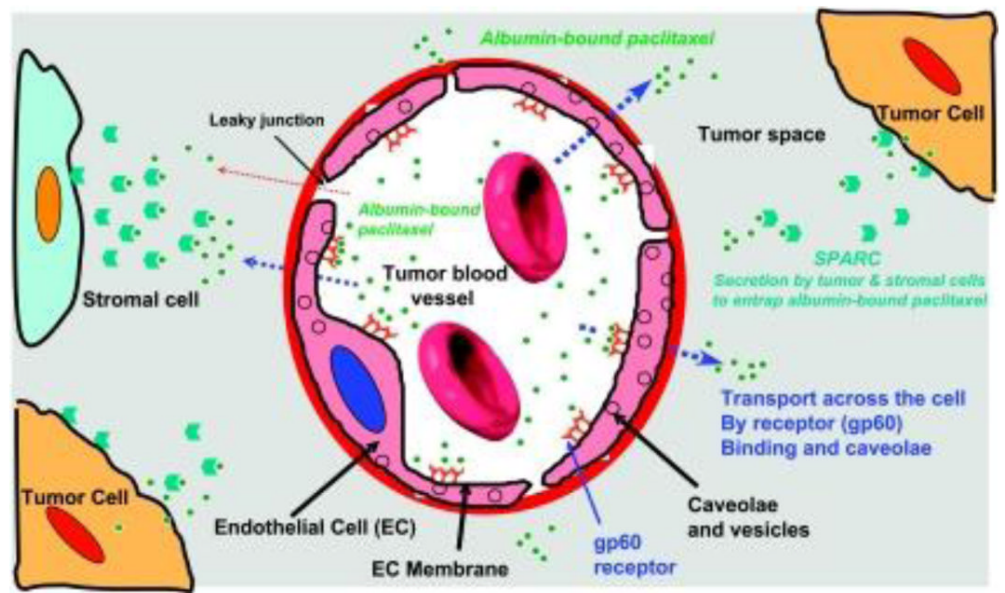

Figure 2.

Mechanisms for the transport and accumulation of albumin-bound paclitaxel in tumors. Binding of albumin-bound paclitaxel complexes to the gp60 receptor and subsequent caveolin-1 mediated transcytosis results in transport across the endothelial barrier of the tumor vasculature. SPARC, an albumin-binding protein present in the tumor interstitium, enhances accumulation of the complexes in tumor tissue. Figure taken from reference [59]. 


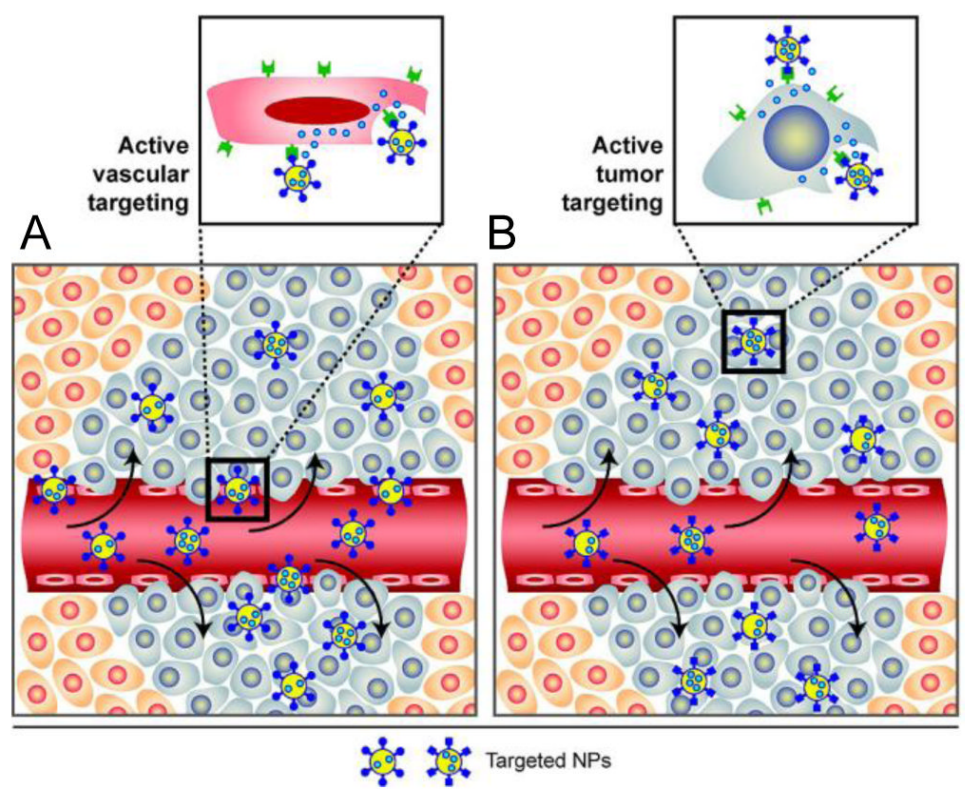

Figure 3.

(A) Nanoparticles with ligands specific for endothelial cell surface markers allow for binding and accumulation to tumor vasculature. (B) Once in the tumor tissue, nanoparticles with ligands specific for tumor cell markers can actively bind to tumor cells, enhancing accumulations and promoting receptor-mediated endocytosis. Figure taken from reference [69]. 

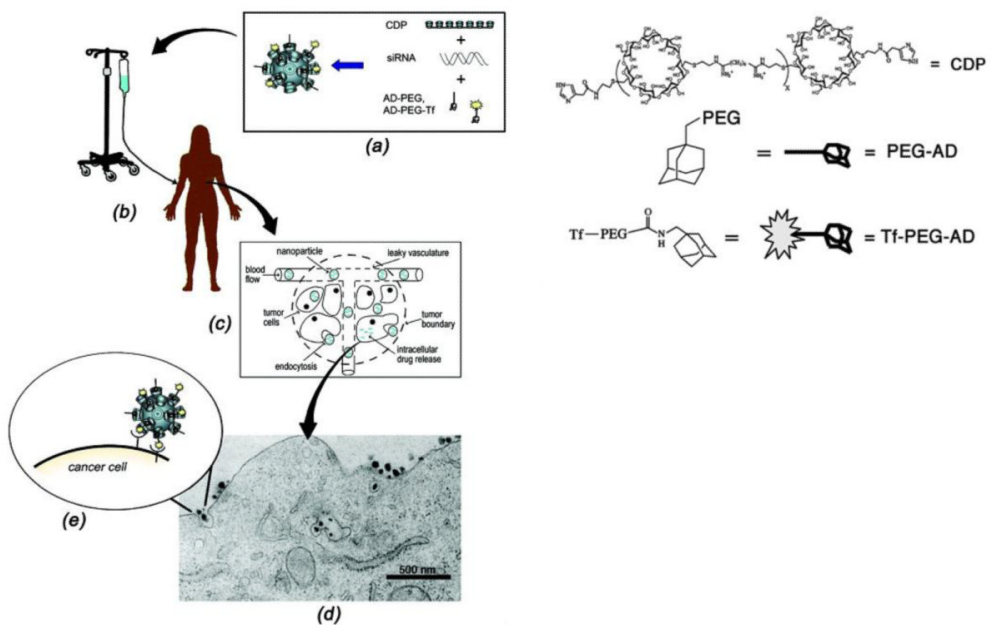

Figure 4.

Assembly and function of targeted cyclodextrin nanoparticles containing siRNA. (a) Nanoparticles consist of four components: (i) a water-soluble, linear cyclodextrin-containing polymer (CDP), (ii) an adamantane (AD)-PEG conjugate (AD-PEG), (iii) the targeting component that has human transferrin (Tf) conjugated to AD-PEG (Tf-PEG-AD), and (iv) siRNA. (b) Aqueous nanoparticle solutions are infused into patients and circulate throughout the body. (c) Nanoparticles accumulate in tumor tissue due to the EPR effect. (D and E) Nanoparticle targeting ligands bind to Tf receptors on tumor cells, resulting in endocytosis (transmission electron micrograph of $50 \mathrm{~nm}$ nanoparticles entering a cancer cell). Figure taken from reference [79]. 


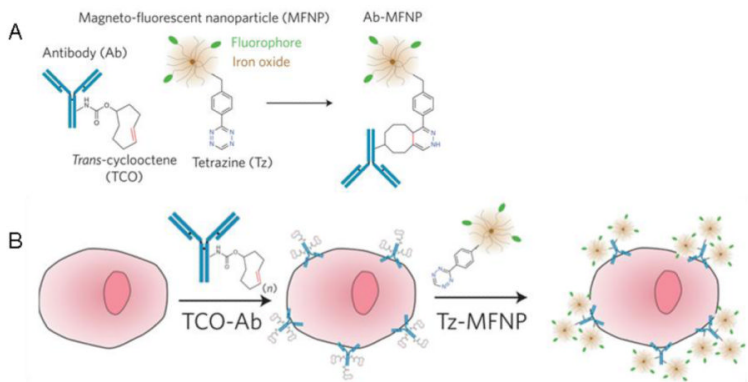

c
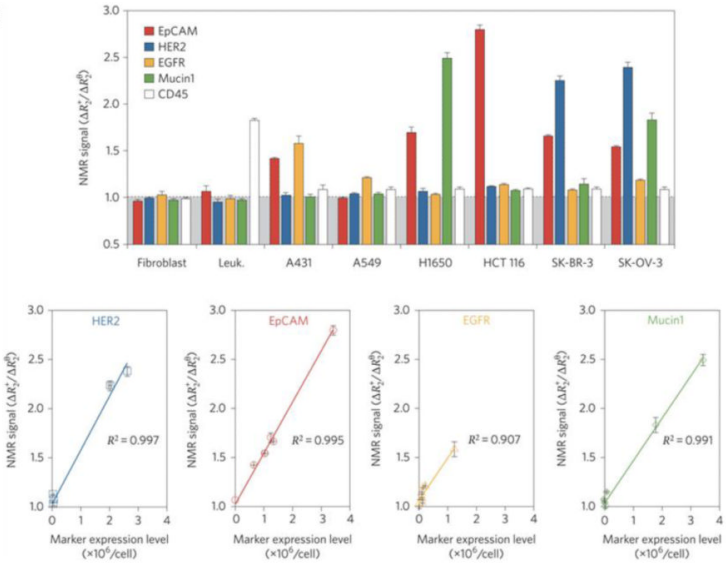

Figure 5.

(A and B) Two-step process for targeting biomarkers on cancer cells. Live cells are labeled with TCO-modified antibodies followed by covalent reaction with Tz-modified fluorescent0labeled iron oxide nanoparticles. (C) Cell profiling using a miniaturized diagnostic magnetic resonance device. Excellent correlation was observed between NMR signals of tumor cells and marker expression levels measured using flow cytometry. Figure taken from reference [102]. 


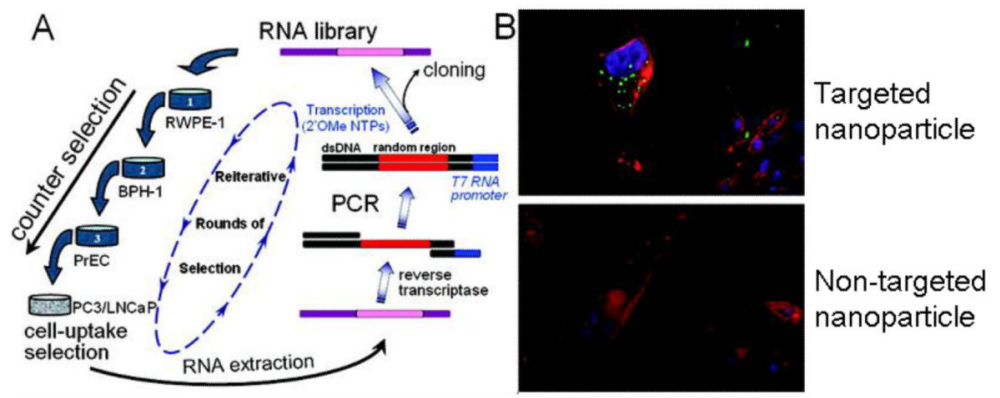

Figure 6.

(A) Cell-uptake selection process for isolating RNA aptamers capable of cell-specific internalization in prostate cancer cells. (B) Visualization of aptamer-functionalized nanoparticle internalization by PC3 cells using confocal fluorescence microscopy. The nucleus is stained blue (DAPI), the cytoskeleton is stained red (rhodamine phalloidin), and the nanoparticles are green (NBD dye). Figure taken from reference [74, 108]. 


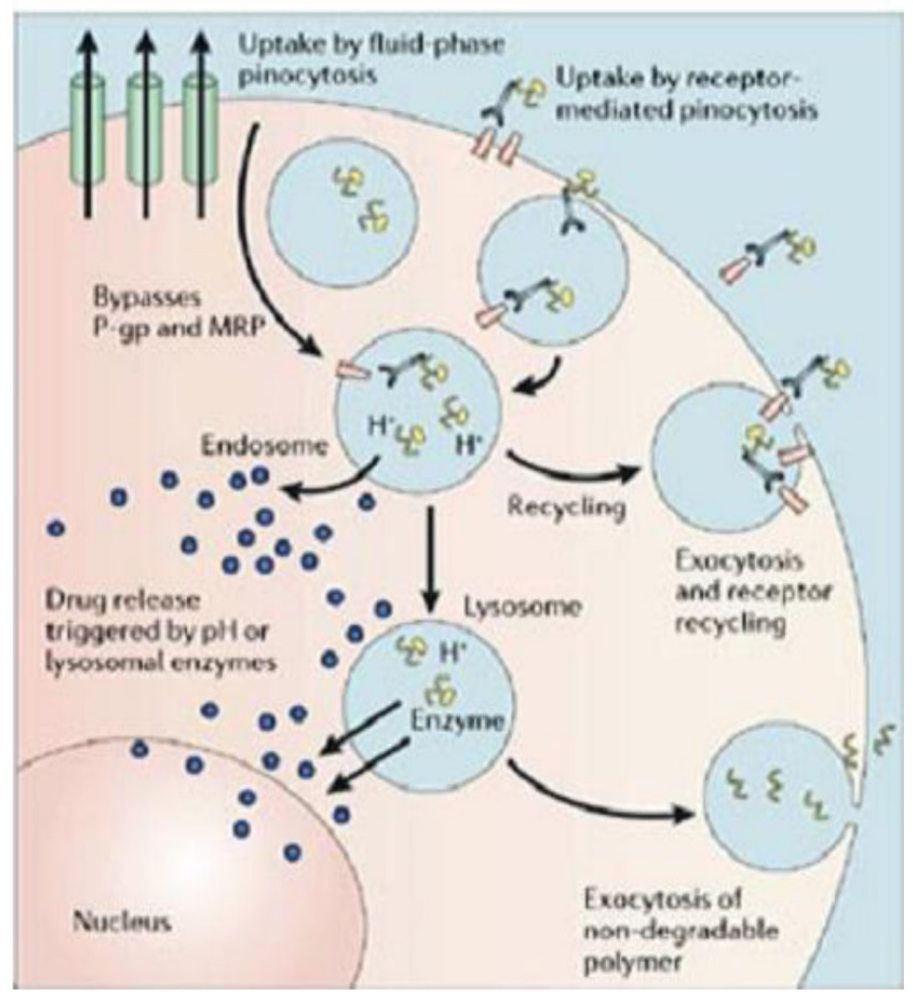

Figure 7.

Tumor cell internalization of polymer-drug conjugates occurs through several possible mechanisms, including fluid-phase pinocytosis (in solution), non-specific membrane binding (due to hydrophobic or charge interactions) resulting in receptor-mediated pinocytosis, or ligand-receptor docking. The linker used to conjugate drug to the polymer allow for intracellular drug release based on a trigger such as exposure to lysosomal enzymes (e.g., Gly-Phe-Leu-Gly is cleaved by cathepsin B) or low pH (e.g., a hydrazone linker degrades in endosomes and lysosomes ( $\mathrm{pH} 6.5$ to $<4.0$ )). Pharmacological targets in the cell are reached by the active or passive transport of drugs out of endosomal or lysosomal vesicles. Intracellular delivery allows drugs to bypass membrane efflux pumps such as p-glycoprotein that aid in drug resistance. Polymers that are not biodegradable can be removed from cells through exocytosis. Figure taken from reference [118]. 


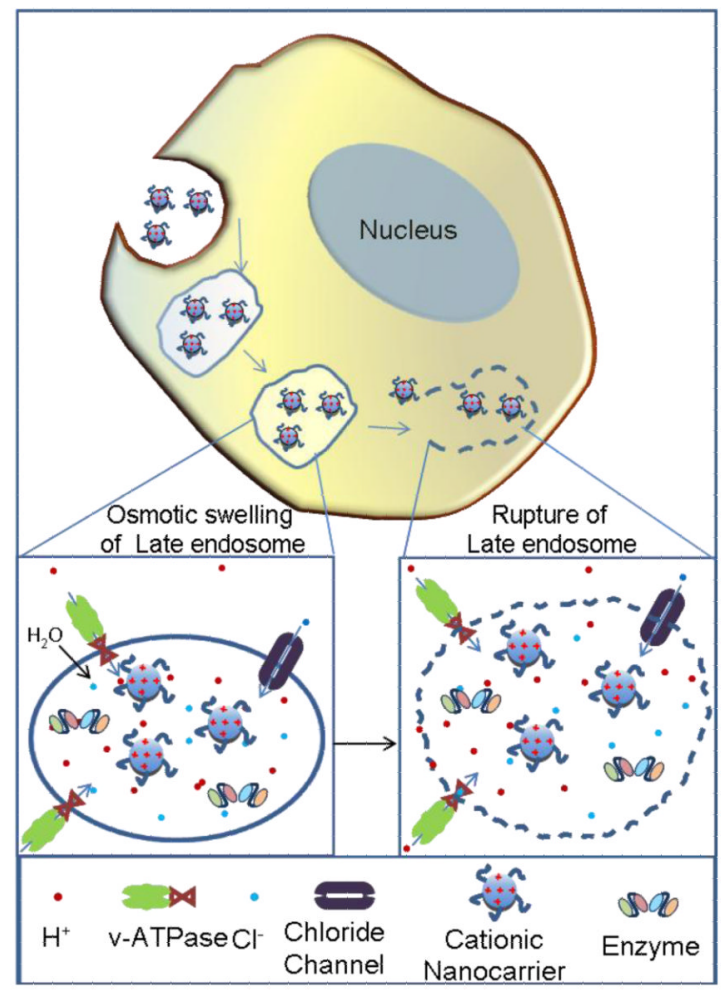

Figure 8.

The proton sponge effect allows for cationic nanoparticles to escape endosomal and lysosomal vesicles and enter the cytoplasm. When cationic nanoparticles enter acidic vesicles, unsaturated amino groups sequester protons supplied by v-ATPase (proton pump). Sequestered protons cause the pump to continue functioning, leading to the retention of chloride ions and water molecules. Eventually, osmotic swelling causes rupture of the vesicle and the cationic nanoparticles are able to enter the cytoplasm. 
(a)

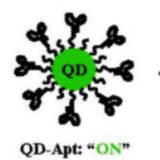

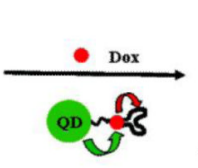

(b)

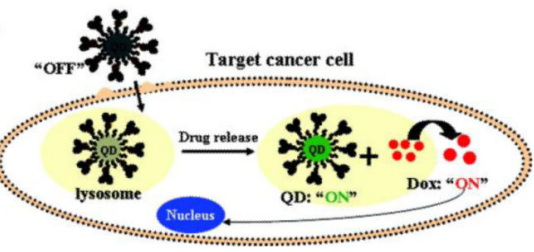

(c)

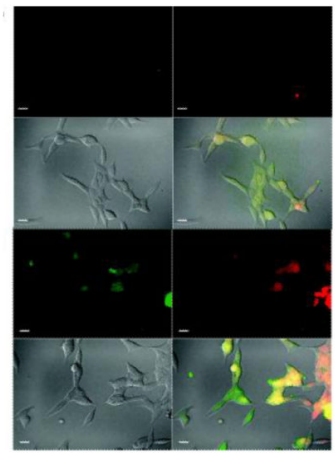

Figure 9.

(a) Schematic of a QD-aptamer (doxorubicin) system capable of fluorescence resonance energy transfer (FRET). Doxorubicin is able to intercalate with the A10 PSMA aptamer bound to the QD surface, quenching both QD and doxorubicin fluorescence through a BiFRET mechanism ("OFF" state). (b) Aptamer targeting results in receptor-mediated endocytosis of QD-aptamer (doxorubicin) conjugates by cancer cells. Doxorubicin release from QD-aptamer (doxorubicin) conjugates results in fluorescence recovery by both QD and doxorubicin ("ON" state). LNCaP cells expressing PSMA were incubated with QD-aptamer (doxorubicin) for $0.5 \mathrm{~h}$ at $37^{\circ} \mathrm{C}$, washed two times with PBS buffer, and further incubated at $37^{\circ} \mathrm{C}$ for (c) $0 \mathrm{~h}$ and (d) $1.5 \mathrm{~h}$ before imaging using confocal laser scanning microscopy. Doxorubicin is shown in red and QDs are shown in green. The lower right images of each panel represent the overlay of doxorubicin and QD fluorescent. The scale bar is $20 \mu \mathrm{m}$. Figure taken from reference [183]. 


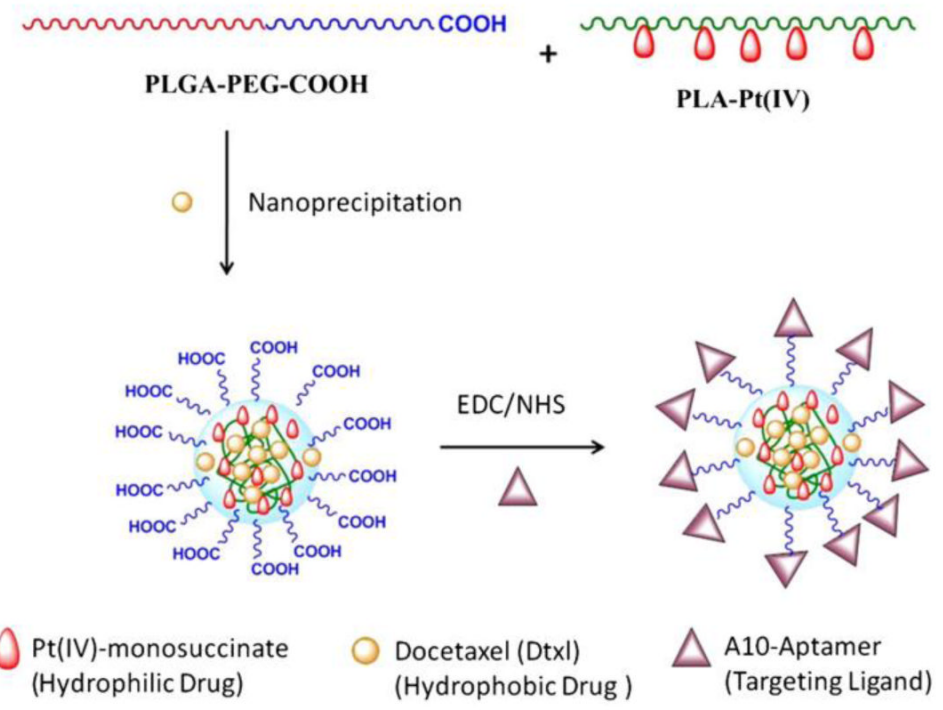

Figure 10.

Pt(IV)-PLA drug conjugates were blended with PLGA-PEG and docetaxel to form nanoparticles capable of delivering chemotherapy drug combinations. The nanoparticle surface was then functionalized with the A10 aptamer to target the nanoparticles to PSMA receptors. Figure taken from reference [192]. 